\title{
Classification of Arctic, midlatitude and tropical clouds in the mixed-phase temperature regime
}

\author{
Anja Costa $^{1}$, Jessica Meyer ${ }^{1, \mathrm{a}}$, Armin Afchine ${ }^{1}$, Anna Luebke ${ }^{1, \mathrm{~b}}$, Gebhard Günther ${ }^{1}$, James R. Dorsey ${ }^{2}$, \\ Martin W. Gallagher ${ }^{2}$, Andre Ehrlich ${ }^{3}$, Manfred Wendisch ${ }^{3}$, Darrel Baumgardner ${ }^{4}$, Heike Wex ${ }^{5}$, and \\ Martina Krämer ${ }^{1}$ \\ ${ }^{1}$ Forschungszentrum Jülich GmbH, Jülich, Germany \\ ${ }^{2}$ Centre for Atmospheric Science, University of Manchester, Manchester, UK \\ ${ }^{3}$ Leipziger Institut für Meteorologie, Universität Leipzig, Germany \\ ${ }^{4}$ Droplet Measurement Technologies, Longmont, CO 80503, USA \\ ${ }^{5}$ Leibniz Institute for Tropospheric Research, Leipzig, Germany \\ ${ }^{a}$ now at: Bundesanstalt für Arbeitsschutz und Arbeitsmedizin, Dortmund, Germany \\ bnow at: Atmosphere in the Earth System Department, Max Planck Institute for Meteorology, Hamburg, Germany
}

Correspondence to: Martina Krämer (m.kraemer@fz-juelich.de)

Received: 10 March 2017 - Discussion started: 23 March 2017

Revised: 7 August 2017 - Accepted: 29 August 2017 - Published: 13 October 2017

\begin{abstract}
The degree of glaciation of mixed-phase clouds constitutes one of the largest uncertainties in climate prediction. In order to better understand cloud glaciation, cloud spectrometer observations are presented in this paper, which were made in the mixed-phase temperature regime between 0 and $-38^{\circ} \mathrm{C}$ ( 273 to $235 \mathrm{~K}$ ), where cloud particles can either be frozen or liquid. The extensive data set covers four airborne field campaigns providing a total of $1390001 \mathrm{~Hz}$ data points (38.6 h within clouds) over Arctic, midlatitude and tropical regions. We develop algorithms, combining the information on number concentration, size and asphericity of the observed cloud particles to classify four cloud types: liquid clouds, clouds in which liquid droplets and ice crystals coexist, fully glaciated clouds after the Wegener-BergeronFindeisen process and clouds where secondary ice formation occurred. We quantify the occurrence of these cloud groups depending on the geographical region and temperature and find that liquid clouds dominate our measurements during the Arctic spring, while clouds dominated by the WegenerBergeron-Findeisen process are most common in midlatitude spring. The coexistence of liquid water and ice crystals is found over the whole mixed-phase temperature range in tropical convective towers in the dry season. Secondary ice is found at midlatitudes at -5 to $-10^{\circ} \mathrm{C}$ ( 268 to $263 \mathrm{~K}$ ) and at higher altitudes, i.e. lower temperatures in the tropics. The
\end{abstract}

distribution of the cloud types with decreasing temperature is shown to be consistent with the theory of evolution of mixedphase clouds. With this study, we aim to contribute to a large statistical database on cloud types in the mixed-phase temperature regime.

\section{Introduction}

Clouds can be classified according to their altitude (low, midlevel, high; see e.g. Rossow and Schiffer, 1991), their temperature (warm, cold) or their cloud particle phase (liquid, mixed-phase: both liquid and ice, ice). Especially for intermediate altitudes, these classification criteria overlap: ice particles may sediment into warm cloud layers, updraughts can transport liquid water droplets into colder cloud regions and droplet formation may produce liquid water content in a cold, formerly glaciated cloud (Findeisen et al., 2015; Korolev, 2007).

To avoid ambiguities, we refer here to all clouds observed at temperatures between 0 and $-38^{\circ} \mathrm{C}$ ( 273 to $\left.235 \mathrm{~K}\right)$ as "clouds in the mixed-phase temperature regime" (mpt clouds). In that temperature regime, purely liquid (supercooled) clouds can be found as well as mixed-phase clouds (where liquid water droplets and ice crystals coexist) and 


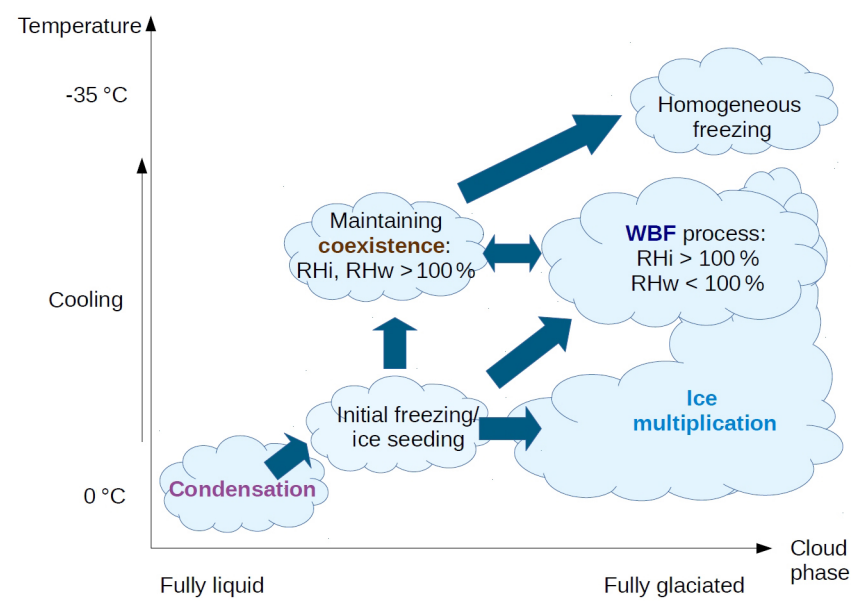

Figure 1. Possible paths to glaciation in the mixed-phase temperature regime.

also fully glaciated clouds (Pruppacher et al., 1998). Within this temperature range, important processes take place that transform the cloud's phase or microphysical characteristics significantly. This phase transition is not only an important part of precipitation-forming processes like the cold rain process, it also affects the cloud's radiative properties by influencing the solar albedo of mpt clouds (Curry et al., 1996; Shupe and Intrieri, 2004): with growing ice fraction, their solar albedo (cooling) effect is reduced (Ehrlich et al., 2009; Wendisch et al., 2013). Thus a correct representation of this cloud type in global climate models is of importance for an improved certainty of climate predictions (Wendisch et al., 2013, 2017).

The transformation from a fully liquid to a fully frozen cloud can follow different, sometimes non-linear paths, as illustrated in Fig. 1. After the activation of cloud condensation nuclei forms small droplets $<50 \mu \mathrm{m}$ (all-liquid state), initial freezing can occur in those droplets that contain or touch an ice nucleating particle (INP) that can be activated in the ambient cloud environment (resulting in a mixed-phase state: coexistence of ice and water). Different INPs can induce ice nucleation at different temperatures, depending on their nature, e.g. whether they are of biological or mineral origin, their morphology and freezing efficiency. Therefore, the number of droplets containing an INP needed to heterogeneously form ice is important for its glaciation, and the temperature of the mpt cloud is also relevant, as the freezing efficiency of different INPs varies with temperature. The INP properties that favour ice formation are a major discussion point in cloud and climate research. The conditions that favour drop freezing are, in a simplified summary, as follows: cold temperatures, high relative humidities and a "good freezing ability". For more details on the specific conditions see e.g. Kanji et al. (2017) and references therein. Biological particles are known to induce ice nucleation in the temperature range between about 0 and $-20^{\circ} \mathrm{C}(273$ to $253 \mathrm{~K})$, while

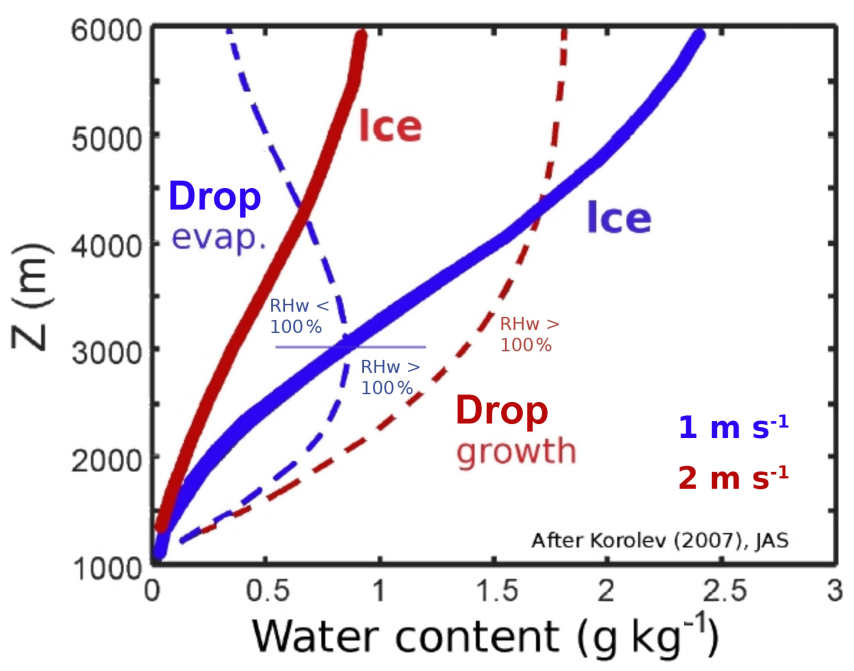

Figure 2. Liquid water content (dashed lines) and ice water content (solid lines) development with altitude $Z(\sim 1 /$ temperature) in mixed-phase clouds for different vertical velocities (adapted from Korolev, 2007, with modification). Blue lines (updraught $1 \mathrm{~m} \mathrm{~s}^{-1}$ ): the cloud glaciates when $\mathrm{RH}_{\mathrm{W}}$ falls below $100 \%$ (WegenerBergeron-Findeisen regime); red lines (updraught $2 \mathrm{~m} \mathrm{~s}^{-1}$ ): $\mathrm{RH}_{\mathrm{W}}$ stays above $100 \%$, liquid droplets and ice crystals coexist (coexistence regime).

mineral dust particles initiate ice at temperatures below about $-20^{\circ} \mathrm{C}$ (Kanji et al., 2017; Augustin-Bauditz et al., 2014).

The persistence of supercooled liquid clouds in case no ice active particles are present is also reported by Korolev (2007). Moreover, the further development of the glaciation degree of a mpt cloud, in which a few ice crystals are present, is discussed in this study in relation to the environmental dynamical conditions. This is illustrated by theoretical considerations (Korolev, 2007) of the partitioning of liquid and ice water content in rising mixed-phase cloud parcels under different conditions (see Fig. 2, adapted from Korolev, 2007). The first scenario represents an intermediate vertical velocity ( $1 \mathrm{~m} \mathrm{~s}^{-1}$; blue lines), where the Wegener-BergeronFindeisen process (Findeisen et al., 2015) is triggered above the altitude marked by the blue line (note that the temperature decreases with increasing altitude), which leads to full glaciation of the cloud. At that point, the relative humidity over water falls below $100 \%\left(\mathrm{RH}_{\mathrm{w}}<100 \%\right)$, as more and more water vapour is consumed by the many small liquid cloud droplets. As a result, these droplets evaporate, decreasing the liquid water content. The RH over ice remains above $100 \%\left(\mathrm{RH}_{\mathrm{i}}>100 \%\right)$, allowing the few ice crystals to grow to large sizes $>50 \mu \mathrm{m}$, thus increasing the ice water content.

In contrast, the red graphs show a scenario for higher vertical velocities $\left(2 \mathrm{~m} \mathrm{~s}^{-1}\right)$. Here, due to the high updraught, the supersaturation is preserved over both water and ice $\left(\mathrm{RH}_{\mathrm{w}}, \mathrm{RH}_{\mathrm{i}}>100 \%\right)$ over the complete altitude range. Subsequently, the liquid and ice water content increase in coexistence and the cloud continues to be only partly glaciated 
(coexistence cloud). These simulations demonstrate that vertical velocity is a major parameter controlling the occurrence of different cloud types, because the updraught is the crucial parameter for possible supersaturations. The supersaturation over water can remain at or above $100 \%$ only in high updraughts, thus allowing coexistence clouds to survive down to about $-38^{\circ} \mathrm{C}(235 \mathrm{~K})$, where the supercooled liquid cloud droplets will freeze homogeneously (Pruppacher et al., 1998; Koop et al., 2000). Also, secondary ice production can take place, producing high number concentrations of small ice particles (see overview in Field et al., 2015, 2017). Examples of known processes are the Hallett-Mossop process (also called rime splintering; see Hallett and Mossop, 1974), drop-freezing (Lawson et al., 2015) and ice-ice collisions (Yano and Phillips, 2011). When one of these processes has started, the remaining liquid fraction of a cloud can glaciate quickly via freezing initiated by ice crystals colliding with supercooled water droplets, even if the conditions for the Wegener-Bergeron-Findeisen (WBF) process are not met.

Evaporation of both numerous small liquid droplets and large ice particles occurs when the environment is subsaturated with respect to both water and ice $\left(\mathrm{RH}_{\mathrm{i}}<100, \mathrm{RH}_{\mathrm{W}}<\right.$ $100 \%$ ), as predicted by Korolev (2007) for downdraught regions within the cloud. If this state persists for a sufficiently long time, the cloud will fully evaporate.

In summary, as illustrated in Fig. 1 and Table 1, four types of mpt cloud are expected to occur: the first type describes clouds with many small (diameter $<50 \mu \mathrm{m}$ ) liquid droplets that often appear at slightly supercooled conditions and with lower frequencies as the temperature becomes colder (Bühl et al., 2013). This cloud type may additionally contain a low concentration of large particles (large droplets from coalescence or ice particles sedimenting from above). The second cloud type is coexistence clouds with a high concentration of small cloud particles $<50 \mu \mathrm{m}$ that can be liquid or frozen. The coexistence cloud type appears at decreasing temperatures in higher updraughts. In case the updraughts are very strong as in tropical convective clouds, the supercooled liquid cloud droplets can reach cold temperature regions around $-38^{\circ} \mathrm{C}(235 \mathrm{~K})$ and freeze homogeneously. Furthermore a third type with a high concentration of small ice particles (diameter $<50 \mu \mathrm{m}$ ) might emerge as a result of secondary ice production, e.g. due to the Hallett-Mossop process at temperatures between -3 and $-8^{\circ} \mathrm{C}(270$ to $265 \mathrm{~K})$ or ice splintering. A fourth cloud type in the case of lower updraughts are fully glaciated WBF clouds. They contain only very few or no small liquid droplets $(<50 \mu \mathrm{m})$, but consist mostly of large ice crystals and are expected to appear with increasing frequency when the temperature decreases.

Due to the manifold interactions between large-scale and small-scale dynamics, aerosol particle/INP availability and complex processes of formation and evolution of supercooled liquid and frozen cloud particles, mpt clouds are not well understood and therefore poorly represented in global climate models (Boucher et al., 2013). As a consequence, the uncertainties concerning the global mpt cloud cover's radiative impact are large. Of particular interest is the partitioning of ice and liquid water, i.e. the glaciation degree. An important step that improves the incomplete understanding of the phase transition processes is taking reliable observations of the different types of mpt cloud. However, cloud-particlephase observations are limited by technical constraints: passive satellite data mostly provide information on cloud tops, and ground-based lidars cannot quantify thick layers of liquid water (Shupe et al., 2008; Storelvmo and Tan, 2015). Active remote sensing techniques have been used to derive liquid and ice water paths for the full depth of the atmosphere (reported in Boucher et al., 2013, p. 580), but are subject to large errors. In situ measurements may cover the full vertical extent (Taylor et al., 2016; Lloyd et al., 2015; Klingebiel et al., 2015), but are restricted to the flight path and have to be analysed carefully (Wendisch and Brenguier, 2013). For in situ data sets in the past, the phase identification often relied on cloud particle sizes. Small cloud particles $<50 \mu \mathrm{m}$ are usually regarded as liquid (see e.g. Taylor et al., 2016). With particle imaging probes like OAPs (optical array probes), more sophisticated shape recognition algorithms can be used (e.g. Korolev and Sussman, 2000), which are nevertheless limited. Usually, they require a minimum number of pixels (corresponding to cloud particles with diameters of $70 \mu \mathrm{m}$ and more) to recognize round or aspherical particles reliably. Due to these limitations, the shape identification of small particles has not been considered in many microphysical cloud studies. In the paper presented here, we use a new detector that can measure the asphericity of small $(<50 \mu \mathrm{m})$ cloud particles (Baumgardner et al., 2014) together with a visual shape inspection of particles $>50 \mu \mathrm{m}$. We thus hope to provide new insights into the microphysical evolution of clouds in the mpt regime.

To this end, we use in situ airborne cloud measurements in the cloud particle size range from 3 to $937 \mu \mathrm{m}$ to classify the above-described types of cloud in the mpt regime (see Fig. 1): mostly liquid clouds occur after drop formation, coexistence clouds after initial freezing, secondary ice clouds are influenced by ice multiplication and large ice clouds occur after the WBF process. This classification enables us to revisit a statistical overview published by Pruppacher et al. (1998), stating at which temperatures purely liquid or icecontaining clouds were found.

For all except the fourth cloud type, we expect high cloud particle number concentrations with a peak at cloud particle sizes $<50 \mu \mathrm{m}$. Thus, particle size distributions and concentrations allow a differentiation between glaciated clouds mainly formed via the WBF process and other cloud types in the mpt regime. To investigate these other types more closely, they are divided into three groups with differing aspherical cloud particle fractions, in agreement with the cloud types described above. The occurrence of the four cloud types is then quantified with regard to measurement location and tem- 
Table 1. Characteristics of the cloud types expected in the mpt regime.

\begin{tabular}{|c|c|c|c|c|}
\hline & $\begin{array}{l}\text { Cloud particle } \\
\text { concentration }\end{array}$ & Particles $D_{\mathrm{p}}<50 \mu \mathrm{m}$ & Particles $D_{\mathrm{p}}>50 \mu \mathrm{m}$ & Dominant mass mode \\
\hline Mostly liquid & high & Liquid & $\begin{array}{l}\text { Drizzle drops/few ice } \\
\text { crystals possible }\end{array}$ & $D_{\mathrm{p}}<50 \mu \mathrm{m}:$ Type $1 \mathrm{a}$ \\
\hline Coexistence & high & $\begin{array}{l}\text { Mostly liquid, } \\
\text { some ice crystals }\end{array}$ & Ice crystals & $D_{\mathrm{p}}<50 \mu \mathrm{m}:$ Type $1 \mathrm{~b}$ \\
\hline Secondary ice & high & Ice crystals & Ice crystals & $D_{\mathrm{p}}<50 \mu \mathrm{m}:$ Type $1 \mathrm{c}$ \\
\hline Large ice/WBF & low & Ice crystals & Ice crystals & $D_{\mathrm{p}}>50 \mu \mathrm{m}:$ Type 2 \\
\hline
\end{tabular}

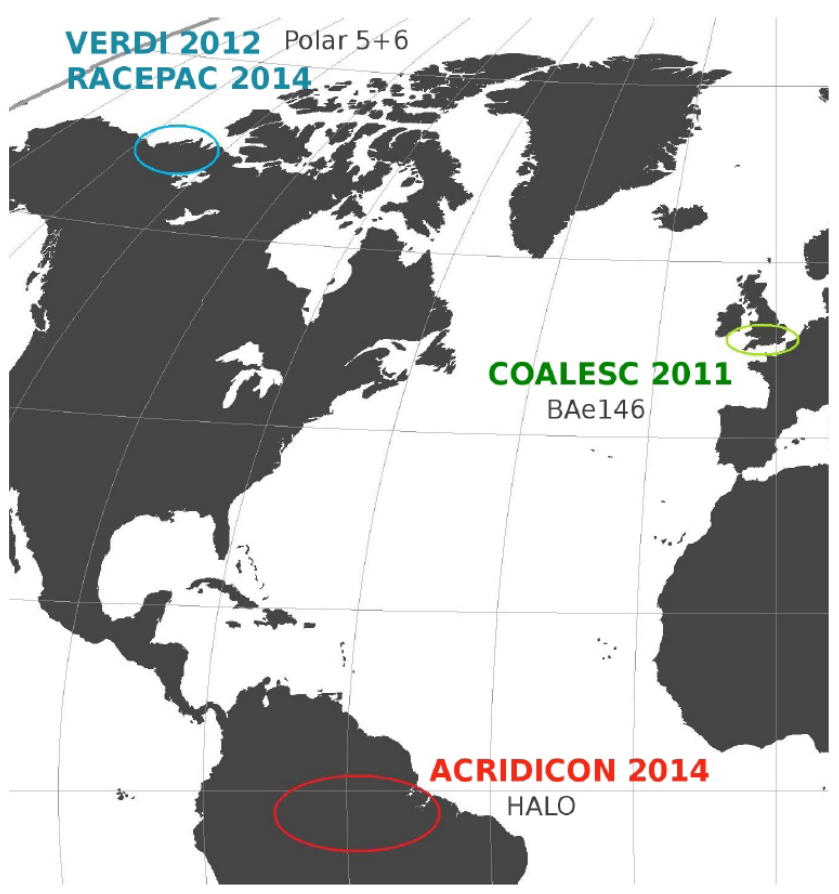

Figure 3. Locations of the campaigns presented in this paper.

perature by performing a statistical analysis of the data obtained by the NIXE-CAPS (New Ice eXpEriment - Cloud and Aerosol Particle Spectrometer) cloud spectrometer with $1 \mathrm{~Hz}$ along the flight path.

The article is structured as follows: in Sect. 2, the field campaigns are described as well as the cloud spectrometer NIXE-CAPS and its data products. In Sect. 3, the observations are evaluated with respect to the clouds' size distribution, the correlation of cloud particle concentrations to expected ice nucleating particle concentrations, the cloud particle asphericity and the associated vertical velocities. Section 4 summarises the findings of this study.

\section{Methodology}

Four airborne field campaigns were performed in Arctic, midlatitude and tropical regions (see Fig. 3 and Sect. 2.1). In total, the data set in the mixed-phase temperature regime between 0 and $-38^{\circ} \mathrm{C}(273$ to $235 \mathrm{~K})$ covers $38.6 \mathrm{~h}$. Mpt clouds were measured using the cloud spectrometer NIXE-CAPS (see Sect. 2.2). The data analysis is described in Sect. 2.3.

\subsection{Field campaigns}

The first campaign, COALESC (Combined Observation of the Atmospheric boundary Layer to study the Evolution of StratoCumulus), was based in Exeter, UK, in February and March 2011. The NIXE-CAPS was installed as a wing probe on the BAe146 aircraft operated by the Facility for Airborne Atmospheric Measurements (FAAM), UK. All flights took place in the coastal area of south-eastern England and Wales; the main campaign targets were low stratus and stratocumulus clouds. The campaign is described in Osborne et al. (2014), Table 2 provides an overview of the flights. Out of 16 measurement flights, 14 provided observations of mpt clouds, with in total 41042 seconds (11.4 h) of data.

Measurements in Arctic clouds have been conducted during the campaigns VERDI (April and May 2012, study on the Vertical Distribution of Ice in Arctic Clouds; see also Klingebiel et al., 2015) and RACEPAC (April and May 2014, Radiation-Aerosol-Cloud Experiment in the Arctic Circle). Both campaigns took place in Inuvik, northern Canada. Research flights were performed with the Polar-5 and Polar-6 aircraft of the Alfred Wegener Institute, Germany. The 13 flights of both VERDI (see Table 3) and RACEPAC (Table 4) covered the region of the Arctic Beaufort Sea coast with its retreating sea ice in spring. VERDI yielded $59028 \mathrm{~s}(16.4 \mathrm{~h})$ of observations within mpt clouds, RACEPAC contributed $33354 \mathrm{~s}(9.3 \mathrm{~h})$. Although both campaigns took place at the same time of the year, different synoptic situations lead to different cloud characteristics: VERDI was dominated by stable anticyclonic periods with weak gradients of atmospheric parameters that allow the formation of a strong inversion in the boundary layer associated with persisting stratus, whereas during RACEPAC frontal systems frequently passed 
Table 2. Flight table for COALESC. Dates are dd/mm/yyyy.

\begin{tabular}{lllr}
\hline Date & Probed clouds/flight objectives & Cloud $T$ in the mpt regime & $\begin{array}{r}\text { Minutes in } \\
\text { mpt clouds }\end{array}$ \\
\hline 15.02.2011 & Warm clouds, mixed clouds, cirrus; test flight & -1.5 to $-37.6^{\circ} \mathrm{C}$ & 85.1 \\
23.02.2011 & Warm clouds, cirrus clouds & 0 to $-37.8^{\circ} \mathrm{C}$ & 11.7 \\
24.02 .2011 & Warm stratocumulus & 0 to $-0.1^{\circ} \mathrm{C}$ & 0.1 \\
26.02 .2011 & Stratocumulus & 0 to $-17.9^{\circ} \mathrm{C}$ & 46.0 \\
01.03 .2011 & Stratocumulus & 0 to $-6.4^{\circ} \mathrm{C}$ & 124.7 \\
02.03 .2011 & Stratocumulus & 0 to $-3.1^{\circ} \mathrm{C}$ & 92.0 \\
03.03 .2011 & Stratocumulus & 0 to $-4.4^{\circ} \mathrm{C}$ & 61.9 \\
05.03.2011 & Stratocumulus & 0 to $-3.3{ }^{\circ} \mathrm{C}$ & 51.4 \\
07.03.2011 & No clouds & - & 0 \\
08.03 .2011 & Warm stratocumulus and cirrus clouds & 0 to $-38.0^{\circ} \mathrm{C}$ & 47.0 \\
11.03 .2011 & Stratocumulus & 0 to $-4.9^{\circ} \mathrm{C}$ & 105.9 \\
14.03 .2011 & Mostly cirrus clouds & -8.9 to $-37.9{ }^{\circ} \mathrm{C}$ & 10.6 \\
15.03 .2011 & Stratocumulus and cirrus & 0 to $-38.0^{\circ} \mathrm{C}$ & 25.8 \\
16.03 .2011 & Stratocumulus & 0 to $-0.3^{\circ} \mathrm{C}$ & 6.7 \\
18.03 .2011 & No clouds & - & 0 \\
19.03 .2011 & Mostly contrail cirrus & -18.1 to $-38.0^{\circ} \mathrm{C}$ & 11.9 \\
\hline
\end{tabular}

Table 3. Flight table for VERDI. Dates are dd/mm/yyyy.

\begin{tabular}{lllr}
\hline Date & Probed clouds/flight objectives & Cloud $T$ in the mpt regime & $\begin{array}{c}\text { Minutes in } \\
\text { mpt clouds }\end{array}$ \\
\hline 25.04.2012 & Low mostly liquid stratus; test flight & -3.7 to $-9.1^{\circ} \mathrm{C}$ & 47.1 \\
27.04 .2012 & Stratus (liquid and ice) over sea ice & -8.1 to $-16.5^{\circ} \mathrm{C}$ & 73.4 \\
27.04 .2012 & Low dissipating clouds over sea ice & -9.1 to $-17.3^{\circ} \mathrm{C}$ & 47.6 \\
29.04 .2012 & Stable stratus over sea ice & -8.4 to $-12.5^{\circ} \mathrm{C}$ & 77.9 \\
30.04 .2012 & Extensive cloud with layer structure & -6.3 to $-19.1^{\circ} \mathrm{C}$ & 212.8 \\
03.05 .2012 & Thin low subvisible clouds & -9.4 to $-12.1^{\circ} \mathrm{C}$ & 56.15 \\
05.05.2012 & Patchy low cloud layer & -8.6 to $-16.8^{\circ} \mathrm{C}$ & 77.9 \\
08.05 .2012 & Mostly supercooled liquid clouds, two layers & -4.9 to $-9.7^{\circ} \mathrm{C}$ & 65.8 \\
10.05 .2012 & Dissolving altostratus layer & -5.5 to $-11.2^{\circ} \mathrm{C}$ & 45.1 \\
14.05 .2012 & Two thin stratus and cumulus & -1.4 to $-5.8^{\circ} \mathrm{C}$ & 41.9 \\
15.05 .2012 & Mostly liquid stratus and a cumulus & -0.7 to $-14.1^{\circ} \mathrm{C}$ & 73.2 \\
16.05 .2012 & Thin, mostly liquid stratus & -1.7 to $-5.3^{\circ} \mathrm{C}$ & 95.2 \\
17.05 .2012 & Mostly liquid stratus with large snow & 0 to $-6.3^{\circ} \mathrm{C}$ & 54.5 \\
\hline
\end{tabular}

the area of the observations and lead to a more variable and short-lived cloud situation.

The tropical measurement campaign ACRIDICONCHUVA (Aerosol, Cloud, Precipitation, and Radiation Interactions and Dynamics of Convective Cloud Systems Cloud processes of the main precipitation systems in Brazil: A contribution to cloud resolving modelling and to the GPM - Global Precipitation Measurement) was carried out in September and October 2014. The instrument platform was HALO (High Altitude and Long Range Research Aircraft), a Gulfstream V aircraft operated by DLR (Deutsches Luftund Raumfahrtszentrum/German Aerospace Centre). Based in Manaus, Brazil, ACRIDICON-CHUVA was aimed at convective clouds over tropical rainforest and deforested areas (see Table 5; for details, see Wendisch et al., 2016). The cam- paign comprises 14 flights, 11 of which contained clouds in the mixed-phase temperature regime. Although cloud profiling at various altitudes and temperatures was a main directive of ACRIDICON-CHUVA, the total time spent within mpt clouds was only 5368 seconds $(1.5 \mathrm{~h})$. The relatively limited time span was caused by the high flying speed of HALO (up to $240 \mathrm{~m} \mathrm{~s}^{-1}$ ); it results in short penetration times (in the range of several seconds) of the convective towers. A second reason is the increasing danger of strong vertical winds and icing in developing cumulonimbus clouds. From certain cloud development stages on, only the cloud's anvil and outflow at cold temperatures lower than $-38^{\circ} \mathrm{C}(235 \mathrm{~K})$ could be probed. 
Table 4. Flight table for RACEPAC. Dates are dd/mm/yyyy.

\begin{tabular}{lllr}
\hline Date & Probed clouds/flight objectives & $T$ range/cloud top $T$ & $\begin{array}{r}\text { Minutes in } \\
\text { mpt clouds }\end{array}$ \\
\hline 28.04.2014 & Cumulus & -12.9 to $-17.8^{\circ} \mathrm{C}$ & 54.1 \\
30.04.2014 & Low-level clouds in cold sector of a low & -2.3 to $-14.4^{\circ} \mathrm{C}$ & 70.2 \\
01.05.2014 & Thin fog layer & -2.0 to $-9.6^{\circ} \mathrm{C}$ & 5.0 \\
03.05.2014 & Single/double layer liquid-dominated cloud & 0 to $-2.4^{\circ} \mathrm{C}$ & 27.2 \\
06.05.2014 & Single/multilayer clouds & 0 to $-6.3^{\circ} \mathrm{C}$ & 55.6 \\
08.05 .2014 & Thick stratus & 0 to $-3.8^{\circ} \mathrm{C}$ & 22.5 \\
10.05 .2014 & Two stratus clouds & -3.0 to $-9.1{ }^{\circ} \mathrm{C}$ & 49.0 \\
11.05 .2014 & No clouds & -- & 0 \\
13.05 .2014 & No clouds & -- & 0 \\
14.05 .2014 & Homogeneous stratus & -1.9 to $-10.1^{\circ} \mathrm{C}$ & 25.8 \\
16.05 .2014 & Mid-level clouds & 0 to $-10.1^{\circ} \mathrm{C}$ & 75.7 \\
17.05 .2014 & Liquid and ice clouds on various altitudes & 0 to $-11.3^{\circ} \mathrm{C}$ & 22.7 \\
20.05 .2014 & Low-level clouds & -1.5 to $-9.5^{\circ} \mathrm{C}$ & 54.2 \\
22.05 .2014 & Low-level clouds before front & -6.1 to $-15.0^{\circ} \mathrm{C}$ & 29.2 \\
22.05 .2014 & Stratus behind front & -1.5 to $-11.8^{\circ} \mathrm{C}$ & 29.6 \\
23.05 .2014 & Mid-level clouds & -2.3 to $-15.1^{\circ} \mathrm{C}$ & 14.3 \\
\hline
\end{tabular}

Table 5. Flight table for ACRIDICON-CHUVA. Dates are dd/mm/yyyy.

\begin{tabular}{lllr}
\hline Date & Probed clouds/flight objectives & Cloud T in the mpt regime & $\begin{array}{r}\text { Minutes in } \\
\text { mpt clouds }\end{array}$ \\
\hline 06.09.2014 & Convective cloud and outflow & 0 to $-32.2^{\circ} \mathrm{C}$ & 13.2 \\
09.09 .2014 & Convective cloud & 0 to $-1.2^{\circ} \mathrm{C}$ & 1.1 \\
11.09 .2014 & Convective cloud and outflow & 0 to $-38.0^{\circ} \mathrm{C}$ & 8.6 \\
12.09 .2014 & Cloud tops for satellite comparison & 0 to $-29.6^{\circ} \mathrm{C}$ & 5.5 \\
16.09 .2014 & Pyrocumulus and outflow & 0 to $-38.0^{\circ} \mathrm{C}$ & 18.1 \\
18.09 .2014 & Shallow convective cloud and outflow & -36.6 to $-38.0^{\circ} \mathrm{C}$ & 1.4 \\
19.09 .2014 & Pyrocumulus, convective outflow & -0.4 to $-35.1^{\circ} \mathrm{C}$ & 8.8 \\
21.09 .2014 & Albedo flight & - & 0 \\
23.09 .2014 & Convective cloud and outflow & 0 to $-38.0^{\circ} \mathrm{C}$ & 5.5 \\
25.09 .2014 & Convective cloud anvil/outflow & -29.4 to $-38.0^{\circ} \mathrm{C}$ & 13.5 \\
27.09 .2014 & Warm clouds over forested and deforested areas & - & 0 \\
28.09 .2014 & Convective cloud & 0 to $-38.0^{\circ} \mathrm{C}$ & 11.1 \\
30.09 .2014 & Albedo flight & - & 0 \\
01.10 .2014 & Convective cloud and outflow & 0 to $-5.6^{\circ} \mathrm{C}$ & 2.6 \\
\hline
\end{tabular}

\subsection{The NIXE-CAPS instrument}

The observations presented here comprise particle number concentrations, size distributions and shape information obtained by NIXE-CAPS. Two instruments are incorporated in NIXE-CAPS (Baumgardner et al., 2001; Meyer, 2012; Luebke et al., 2016): the NIXE-CAS-DPOL (Cloud and Aerosol Spectrometer with detector for polarization) and the NIXE-CIPg (Cloud Imaging Probe greyscale). In combination, particles with diameters between 0.61 and $937 \mu \mathrm{m}$ can be sized and counted. NIXE-CAPS measurements are thus split into an aerosol data set (particle diameters 0.61 to $3 \mu \mathrm{m}$ ) and cloud particle data set (i.e. hydrometeors with diameters of 3 to $937 \mu \mathrm{m})$. For aircraft speeds between 240 and $80 \mathrm{~m} \mathrm{~s}^{-1}$, the instruments' sampling volumes limit the par- ticle concentration measurements to concentrations above 0.02 to $0.05 \mathrm{~cm}^{-3}$ (NIXE-CAS-DPOL) and about 0.0001 to $0.001 \mathrm{~cm}^{-3}$ (NIXE-CIPg; the exact values depend on the particle size; see Knollenberg, 1970). The instrument is mounted below the aircraft wing. A detailed description of the operating principles, limitations and uncertainties can be found in Meyer (2012) and Baumgardner et al. (2017). The overall measurement uncertainties concerning particle concentrations and sizes are estimated to be approximately $20 \%$ (Meyer, 2012).

As an improvement over former instrument versions, NIXE-CAPS was modified to minimise ice crystal shattering on the instrument housing, because those ice fragments can artificially enlarge the ice particle concentrations (Field et al., 

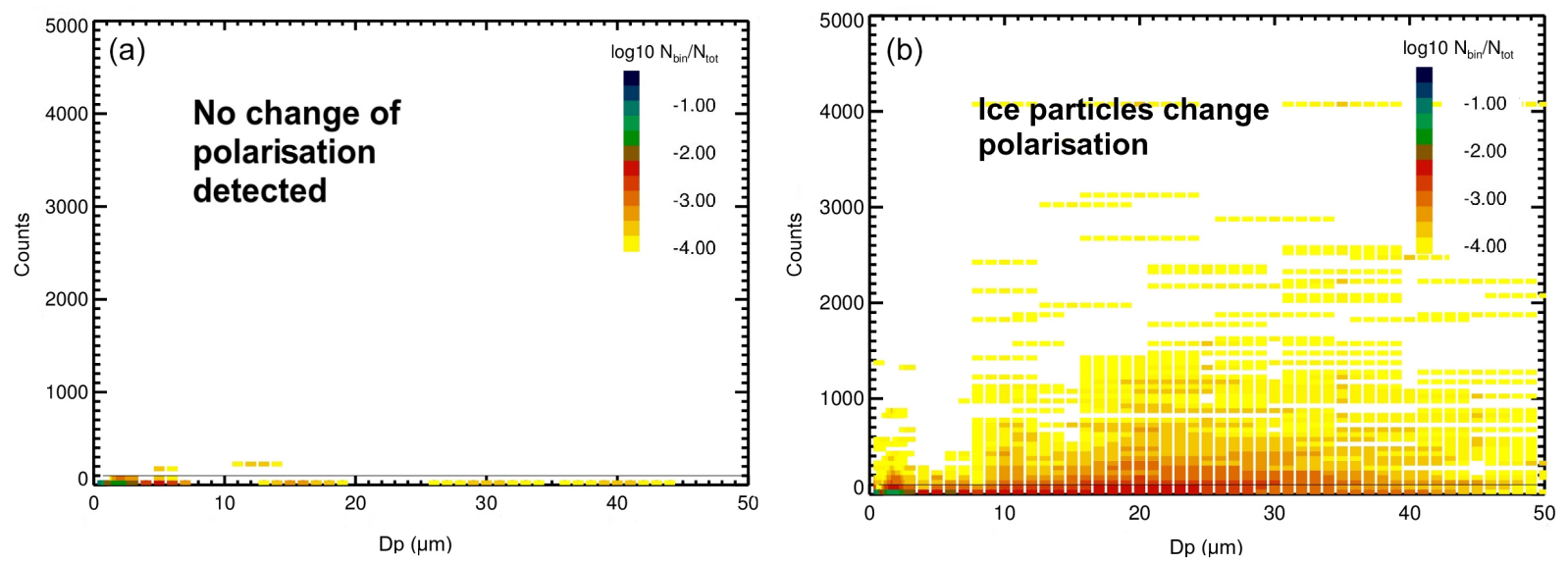

Figure 4. (a) Cross-polarised (S-pol) counts vs. particle size in a warm liquid cloud observed in the ACRIDICON-CHUVA campaign. The colour code denotes the relative frequency of particles in this bin $\left(N_{\text {bin }}\right)$ to overall particle count $\left(N_{\text {tot }}\right)$. The horizontal line in the bottom of the panels shows the signal intensity in the S-pol detector which must be exceeded for a particle to be detected as aspherical. The spherical particles cause a weak signal in the S-pol detector. Right panel shows the same, but in a cold cloud $\left(-60^{\circ} \mathrm{C}, 213 \mathrm{~K}\right)$ consisting of ice crystals. Ice crystals can cause strong signals in the S-pol detector.

2006; Korolev and Field, 2015). Therefore, the tube inlet of the NIXE-CAS-DPOL has been sharpened to a knife edge, and K-tips have been attached to the NIXE-CIPg's arms (Korolev et al., 2013; Luebke et al., 2016).

In the following, we present an overview of the two instrument components NIXE-CAS-DPOL and NIXE-CIPg as well as the data analysis.

\subsubsection{NIXE-CAS-DPOL - particle asphericity detection}

The NIXE-CAS-DPOL (hereafter referred to as the CAS) covers the small particle size range between 0.61 and $50 \mu \mathrm{m}$. As particles pass through the spectrometer's laser beam, the forward-scattered light intensity is used for particle sizing (Baumgardner et al., 2001). As a new feature, the CAS records the change of polarisation in the backward-scattered light, thus giving information about the particle asphericity (Baumgardner et al., 2014). Light scattered by spherical particles in the near-backward direction $\left(168-176^{\circ}\right)$ will retain the same angle of polarisation as the incident light. In contrast, depending on the amount of asphericity, light scattered by non-spherical particles will have some components that are not at the same incident light polarisation. The CAS uses a linearly polarised laser and two detectors that measure the backscattered light. One detector is configured to only detect scattered light with polarisation that is perpendicular (cross-polarised) to the incident light. This signal is referred to as S-pol. In Fig. 4, we show that the intensity of the S-pol signal generates characteristic values for both spherical and aspherical particles. The signature of spherical particles is measured in warm cloud sections $\left(T>0{ }^{\circ} \mathrm{C} / 273 \mathrm{~K}\right)$, if possible during each measurement campaign. Figure 4 shows an example obtained during the ACRIDICON-CHUVA cam- paign: measurements of the cross-polarised light as a function of cloud particle size are shown for both a liquid and a glaciated cloud. The liquid spherical particles cause only a very weak S-pol signal. From this measurement, we derive an asphericity threshold (see black line in Fig. 4), providing a method to distinguish between spherical and aspherical particles. This asphericity threshold is verified, if possible, during each of the airborne campaigns by analysing a flight segment in clouds warmer than $0{ }^{\circ} \mathrm{C}(273 \mathrm{~K})$. The $\mathrm{S}$-pol signal caused by ice particles is shown in Fig. 4a for a cirrus cloud (at $-60{ }^{\circ} \mathrm{C} / 213 \mathrm{~K}$ ). Clearly, the ice crystals cause strong S-Pol signals above the asphericity threshold. It can also be seen that the signal strength depends on the size of the crystals. In particular, the instrument sensitivity with regard to particle asphericity decreases for particles smaller than $20 \mu \mathrm{m}$ (note that the particles with diameters smaller than $3 \mu \mathrm{m}$ are aerosol particles). This was found during the experiments described by Järvinen et al. (2016), who compared several asphericity detection methods, including the CAS. Järvinen et al. (2016) also show that ice crystals can be near spherical. The low signal caused in the CAS polarisation detector by this type of crystal can lead to an underestimation of the glaciation degree of a mixed-phase cloud if it is derived from aspherical cloud particle fractions (see also Nichman et al., 2016). In addition, there are variations in the S-pol signals that are caused by the orientation of the crystal with respect to the laser beam (Baumgardner et al., 2014).

Taking into account these uncertainties, we find that it is possible to use the S-pol signal for a classification of $\mathrm{mpt}$ clouds. Firstly, we perform the asphericity analysis only for particle sizes between 20 and $50 \mu \mathrm{m}$, the range with the strongest S-pol signal. For this size range, we derive aspherical fractions (AFs) as the percentage of aspherical particles 
per second, which means that particle bulk properties are analysed, not single particle signatures alone. Secondly, we do not interpret each aspherical fraction measurement alone, but divide the AFs into three groups: (i) $\mathrm{AF}$ is $0 \%$ (zero), (ii) $\mathrm{AF}$ is $0-50 \%$ (low) and (iii) $\mathrm{AF}$ is $50-100 \%$ (high).

\subsubsection{NIXE-CIPg}

The NIXE-CIPg (called CIP from here on) is an optical array probe (OAP) that nominally records particles between 7.5 and $960 \mu \mathrm{m}$. Shadow image pixels are defined by shadow intensities of 100-65, 65-35 and 35-0\% of the incident light. Particle sizes and concentrations are derived by using the SODA2 programme (Software for OAP Data Analysis, provided by A. Bansemer, National Center for Atmospheric Research NCAR/University Corporation for Atmospheric Research UCAR, 2013). For a detailed description of SODA2, see for example Frey (2011). Pixels with shadow intensities of $35 \%$ and higher were used for the image analysis. In the observations presented here, only the number concentrations for particles with diameters $>22 \mu \mathrm{m}$ are taken from the CIP data set. The smaller particle fraction is covered by the CAS measurements. The shadow images can be analysed for particle asphericity using various algorithms (Korolev and Sussman, 2000); in this study, however, the occurrence of irregular (i.e. ice) particles was verified manually.

\subsection{Data analysis}

NIXE-CAPS records four individual data sets: histogram and particle by particle (PBP) data for each of the CIP and the CAS instruments. All data sets are evaluated using the NIXElib library (Meyer, 2012; Luebke et al., 2016). In the $1 \mathrm{~Hz}$ histogram data sets, particles are sorted into size bins according to predefined forward-scattering cross sections (CAS) or maximum shadow diameters (CIP). These histograms are created for every second.

The PBP data set recorded by the CIP consists of a time stamp and the shadow image of each individual particle. The shadow images can be analysed with regard to maximum diameter, equivalent size, area ratio and shape. The CAS PBP data are limited to 300 particles per second. For these particles, detailed information is stored: the forward-, backward P-pol- and backward S-pol-scattering intensities, a time stamp and the particle interarrival time.

Apart from the asphericity analysis, this data set also allows a diagnosis of ice crystal shattering following Field et al. (2006) and Korolev and Field (2015). Thus, an interarrival time (IAT) correction was applied (Field et al., 2006) additionally to the instrument modifications described above. This correction rejects particles if their IATs are significantly shorter than those of majority of ice crystals, as these short IATs might result from shattering. IAT histograms compiled during the data analysis showed only very few measurements with short IATs, during which a maximum of about $5 \%$ of the cloud particle population might result from shattering.

\section{Results and discussion}

\subsection{Mpt cloud classification based on particle number size distributions}

Four cloud types are expected in the mpt regime (see Table 1). As mentioned in the introduction, however, only two typical particle number size distributions (PSDs) are found frequently in mpt clouds. Figure 5 shows NIXE-CAPS PSDs measured during VERDI flight 08 , where both types alternate: some cloud regions show very high particle concentrations of small particles with a mode diameter $<50 \mu \mathrm{m}$ (see example of PSD in the lower-right corner). Alternatively, the clouds consist mostly of large ice crystals $>50 \mu \mathrm{m}$ with either no small particles or concentrations below the NIXECAS detection limit (see example of PSD in the lower-left corner).

As a first step of the mpt cloud classification, we sort all clouds according to their particle size distribution type and address these types separately. To this end, we calculate two cloud particle number concentrations: one for particles with diameters between 3 and $50 \mu \mathrm{m}\left(N_{\text {small }}\right)$ and one for all larger particles $\left(N_{\text {large }}\right)$. For the classification of the first cloud type (Type 1$), N_{\text {small }}$ must exceed $1 \mathrm{~cm}^{-3}$, while $N_{\text {large }}$ can be zero or larger. The mode of the cloud particle mass distribution is at particle diameters $<50 \mu \mathrm{m}$. We assume that this type matches the young clouds after droplet condensational growth in Fig. 1. In the second cloud type (Type 2) we classify those clouds with $N_{\text {small }}$ below $1 \mathrm{~cm}^{-3}$ and $N_{\text {large }}$ present. The mode of the cloud particle mass distribution is here at particle diameters $>100 \mu \mathrm{m}$. This type matches fully glaciated clouds, e.g. as a result of the WBF process (see Fig. 1).

In Fig. 6, a histogram is provided that shows the occurrence of cloud particle concentrations throughout our data set. The spectrum of observed concentrations is continuous, but the two modes associated with the Type 1 and Type 2 clouds (as described above) are clearly visible. The area between the two modes (a total of $6 \%$ of all observations) might result from clouds in a transition state to glaciation. In this study, these measurements were assigned to Type 1 clouds. In addition to the two modes, a small peak at very low cloud particle concentrations (about $10^{-4} \mathrm{~cm}^{-3}$ ) indicates slightly elevated concentrations around the detection limit of the CIP (a total of $5 \%$ of all observations). We assume that these are measurements in precipitation, especially in snow that occurred frequently in the Arctic campaigns and in sedimenting aggregates of ice crystals from tropical convective clouds (see Sect. 3.3).

In the following, we discuss the cloud types described above in more detail. Type 1 cloud characteristics measured 


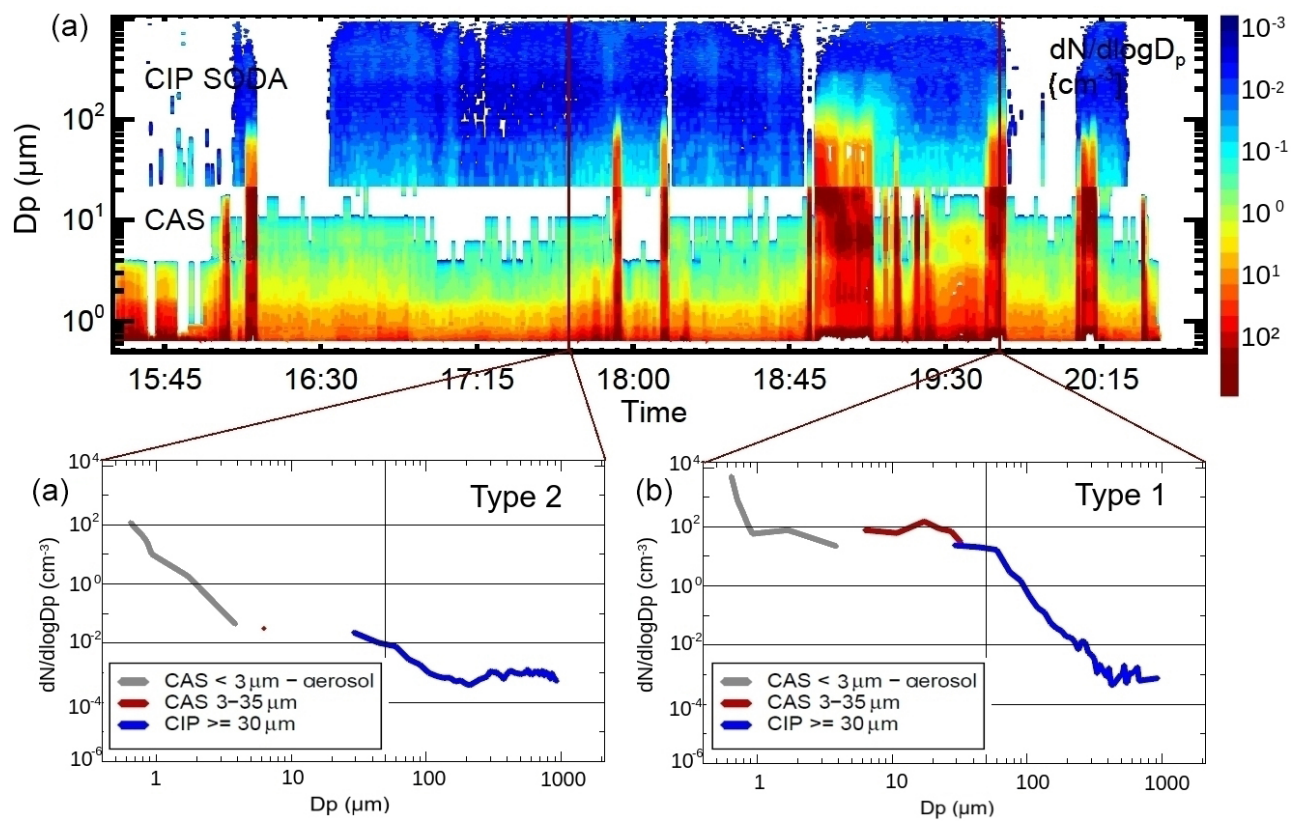

Figure 5. Upper panel: size distributions along time during flight 08 of the VERDI campaign (colour $\operatorname{code}: \mathrm{d} N / \mathrm{dlog} D_{\mathrm{p}}$ ). Two types of cloud can be distinguished; one is dominated by the large particle mode (Type 2, example in lower a), the second by small particles (Type 1 , example in lower b). The two cloud types are also associated with strongly differing particle number concentration ranges; see Fig. 6.

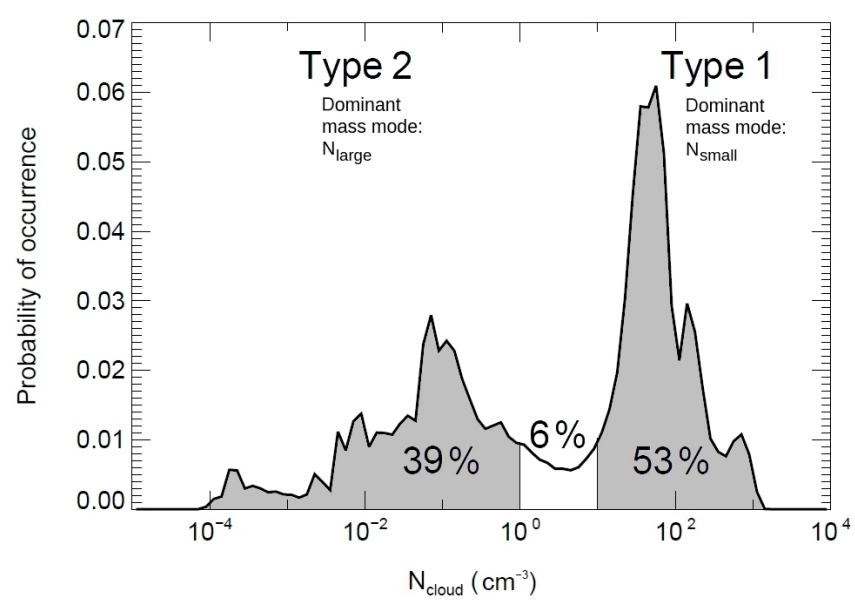

Figure 6. Histogram of cloud particle concentrations $\left(D_{\mathrm{p}} 3\right.$ to $937 \mu \mathrm{m})$ of Type 1 and Type 2 clouds in the mixed-phase temperature regime between 0 and $-38^{\circ} \mathrm{C}$ ( 273 to $\left.235 \mathrm{~K}\right)$. For cloud type definitions see Sect. 3.1. The $6 \%$ between the two clear modes were classified as "Type 1" in this study. $N_{\text {small }}$ is particles with diameters between 3 and $50 \mu \mathrm{m}$. $N_{\text {large }}$ is particles with diameters $>50 \mu \mathrm{m}$. $N_{\text {cloud }}$ is all particles with diameters of $3 \mu \mathrm{m}$ and larger.

during all campaigns are shown in Fig. 7. These clouds have a clear mode between 3 and $50 \mu \mathrm{m}$ and are very dense, while cloud particle number concentrations reach average values of dozens to more than $200 \mathrm{~cm}^{-3}$. Table 6 shows average cloud particle concentrations for the Type 1 clouds at $5 \mathrm{~K}$ intervals. Low number concentrations of large ice particles $>50 \mu \mathrm{m}$ are sometimes found, but all clouds of this type are dominated by $N_{\text {small, }}$, which may consist of liquid droplets, frozen droplets or small ice from ice multiplication processes. With regard to the concentrations of $N_{\text {small }}$ in the different temperature intervals (Fig. 7 and Table 6), it can be clearly seen that they decrease with decreasing temperature. When a cloud consists of liquid droplets, they grow by condensation when lifted to higher altitudes - and thus colder temperatures followed by an increasing coalescence of the droplets, which consequently causes a higher number of $N_{\text {large }}$ while depleting the concentration of small droplets. This is also visible in Fig. 7. Note, however, that $N_{\text {large }}$ also decreases with increasing temperature, reaches a minimum around $260 \mathrm{~K}$ and then rises again, possibly reflecting the increasing occurrence of sedimenting particles. Visual inspection of the CIP images indicates that in the $N_{\text {large }}$ cloud mode ice crystals can be found in addition to the drizzle drops. Three of the cloud types of the mpt regime are expected to show Type 1 cloud characteristics: liquid, coexistence and secondary ice clouds (Types $1 \mathrm{a}, 1 \mathrm{~b}$ and $1 \mathrm{c}$ ).

The second set of PSDs (Type 2: Fig. 8) is not strongly dominated by $N_{\text {small }}$. Here, $N_{\text {large }}$ form a distinct mode. Both mode concentration and maximum values decrease with decreasing temperatures. Clouds of this PSD type have low number concentrations of, on average, less than $0.1 \mathrm{~cm}^{-3}$ in the size range 3 to $50 \mu \mathrm{m}$ (see Table 6). For the sizes $>50 \mu \mathrm{m}$, the CIP images show ice crystals or aggregates. This is the typical appearance of a fully glaciated cloud, formed either via the WBF process during which the small 

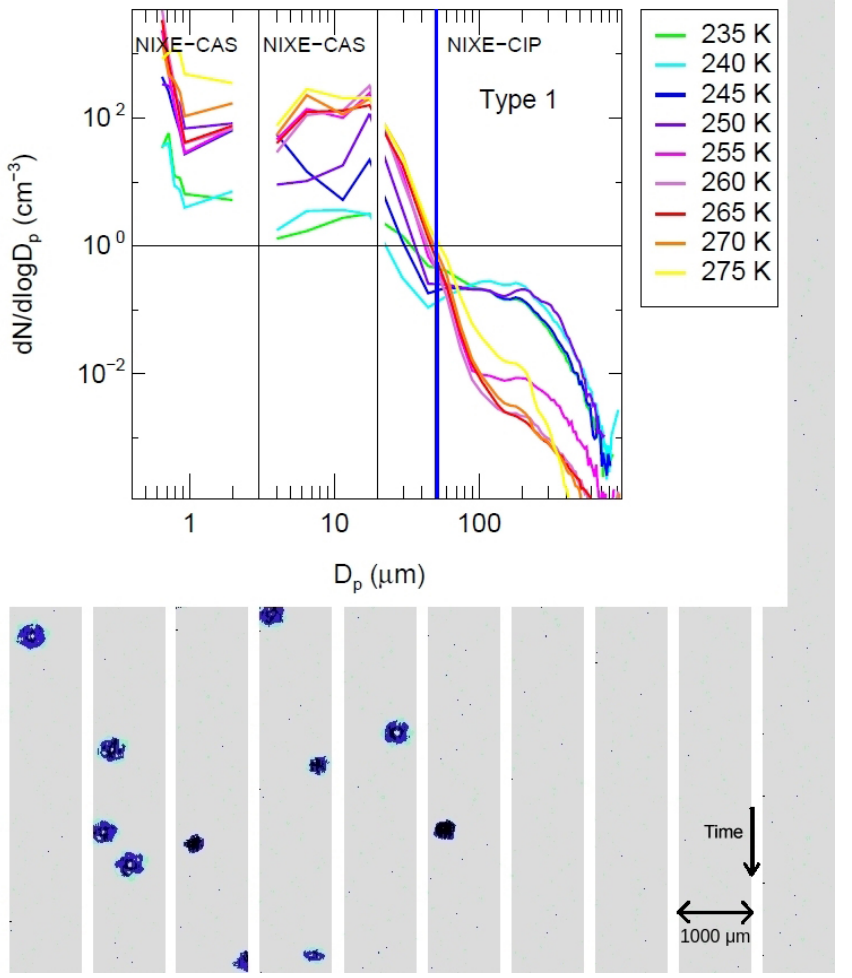

Figure 7. Type 1 clouds: example of CIP images (background picture). The stripes represent a series of CIP shadow images, depicting the particles that have passed subsequently through the detector. Foreground: average particle size distributions (PSDs) in $5 \mathrm{~K}$ intervals, all campaigns. The thin vertical line at $3 \mu \mathrm{m}$ marks the boundary between aerosol and cloud particles. The line at $20 \mu \mathrm{m}$ marks the transition from the NIXE-CAS-DPOL to the NIXE-CIPg instrument. The thick blue line divides the cloud particle population into particles smaller and larger than $50 \mu \mathrm{m}$.

liquid droplets evaporate or at lower altitudes (higher temperatures), due to sedimentation, when aggregates precipitate from higher levels. Again, the two temperature groups are seen as for the Type 1 clouds (Fig. 7), with a clear accumulation of mass at larger particle sizes for temperatures below $247.5 \mathrm{~K}$. An explanation could be that Type 2 clouds most probably develop from Type 1: once the environment becomes subsaturated $\left(\mathrm{RH}_{\mathrm{w}}<100, \mathrm{RH}_{\mathrm{i}}>100 \%\right)$, all liquid droplets evaporate, leaving only the ice crystals that have already formed, e.g. via immersion freezing or ice seeding. Therefore, $N_{\text {large }}$ of Type 2 is only a fraction of those of Type 1, which might reflect the number of active INPs in the respective temperature interval in the case that no ice multiplication takes place (see Sect. 3.2). Thus, the larger differences between the two temperature groups - as seen for Type 1 clouds - more or less balance out. Indeed, an increase in average ice crystal numbers can be seen (Table 6, bottom, $N_{\text {large }}$ ), which might be interpreted as an increasing fraction of activated INPs with decreasing temperature. Note that $N_{\text {small }}$ is still larger than $N_{\text {large }}$. Since shattering artefacts
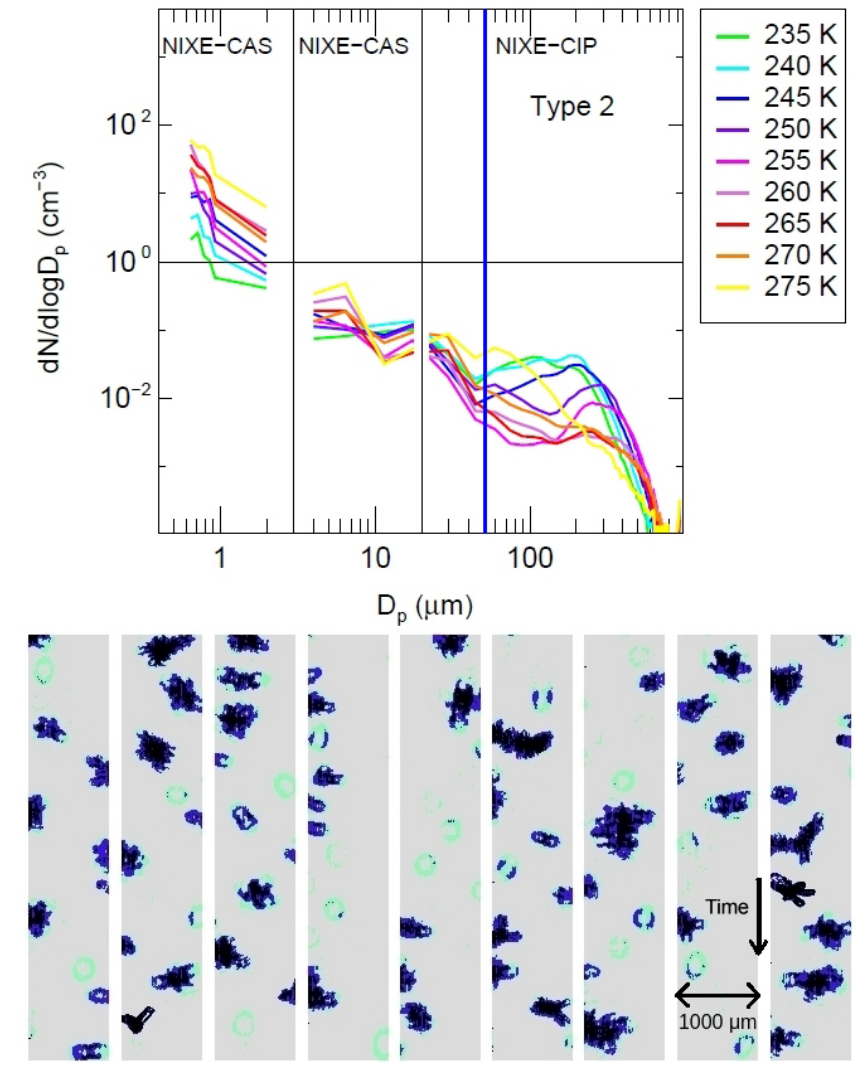

Figure 8. Same as in Fig. 7 but for Type 2 clouds.

are unlikely (see Sect. 2.3), this means that in Type 2 clouds, a significant number of small particles also persist over the whole temperature range.

In addition to these two types, thin clouds with only low concentrations (less than $\left.1 \mathrm{~cm}^{-3}\right)$ of small particles $(<$ $50 \mu \mathrm{m})$ and no large particles are sometimes found, which are most likely evaporating clouds. They are not considered a separate cloud type, since they do not appear frequently and cannot be regarded as a distinct type, they are remnants of one of the two cloud types defined above. Further, the respective measurements stem from the CAS instrument alone and are close to its detectable concentration limit, thus suffering from an enhanced uncertainty.

\subsection{Comparison of cloud particle with ice nucleating particle numbers}

A comparison of the measured cloud particle number concentrations to INP concentrations $\left(N_{\text {INP }}\right)$ can indicate whether the ice particles may result from primary ice nucleation. No direct INP measurements are available for our data set, so we estimated $N_{\text {INP }}$ using the formula provided by DeMott et al. (2010), for which aerosol number concentrations of particles between 0.5 and $3 \mu \mathrm{m}$ are related to INP concentrations. NIXE-CAPS records particles larger than $0.6 \mu \mathrm{m}$; the fraction from 0.6 to $3 \mu \mathrm{m}$ is used as the aerosol frac- 
Table 6. Average cloud particle concentrations for the two cloud types defined in Sect. 3.1 (see also Fig. 5), for both small $\left(D_{\mathrm{p}}<\right.$ $50 \mu \mathrm{m})$ and large $\left(D_{\mathrm{p}}>50 \mu \mathrm{m}\right)$ cloud particles.

\begin{tabular}{lrr}
\hline Type 1 & $N_{\text {small }}\left(\mathrm{cm}^{-3}\right)$ & $N_{\text {large }}\left(\mathrm{cm}^{-3}\right)$ \\
\hline $235 \mathrm{~K}$ & 2.207 & 0.162 \\
$240 \mathrm{~K}$ & 2.632 & 0.177 \\
$245 \mathrm{~K}$ & 19.894 & 0.134 \\
$250 \mathrm{~K}$ & 24.902 & 0.166 \\
$255 \mathrm{~K}$ & 109.944 & 0.035 \\
$260 \mathrm{~K}$ & 109.798 & 0.022 \\
$265 \mathrm{~K}$ & 269.979 & 0.032 \\
$270 \mathrm{~K}$ & 166.362 & 0.047 \\
$275 \mathrm{~K}$ & 67.788 & 0.098 \\
\hline Type 2 & $N_{\text {small }}\left(\mathrm{cm}^{-3}\right)$ & $N_{\text {large }}\left(\mathrm{cm}^{-3}\right)$ \\
\hline $235 \mathrm{~K}$ & 0.057 & 0.023 \\
$240 \mathrm{~K}$ & 0.08 & 0.025 \\
$245 \mathrm{~K}$ & 0.069 & 0.017 \\
$250 \mathrm{~K}$ & 0.062 & 0.01 \\
$255 \mathrm{~K}$ & 0.064 & 0.004 \\
$260 \mathrm{~K}$ & 0.14 & 0.003 \\
$265 \mathrm{~K}$ & 0.07 & 0.003 \\
$270 \mathrm{~K}$ & 0.116 & 0.005 \\
$275 \mathrm{~K}$ & 0.117 & 0.017 \\
\hline
\end{tabular}

tion. Due to the slightly smaller range of our aerosol measurements, the $N_{\text {INP }}$ might be underestimated. However, we believe that this uncertainty is small in comparison to that of the parameterisation by DeMott et al. (2010) itself, since (i) the difference at the lower sizes is only 0.1 micrometre and (ii) aerosol particles larger than 3 micrometres contribute only very little to the concentration of particles larger than 0.5 micrometre (see e.g. Lachlan-Cope et al., 2016). The purpose of using $N_{\text {INP }}$ derived in the described way is to show the differences found between the measurement campaigns and temperature ranges.

The results for $N_{\text {INP }}$ are shown in Fig. 9 as a function of temperature. Generally, $N_{\text {INP }}$ increases with decreasing temperature, as already mentioned in the last section. The most frequent $N_{\text {INP }}$ range is between the lowest calculated value of $10^{-4}\left(0.1 \mathrm{~L}^{-1}\right)$ and $\sim 10^{-3} \mathrm{~cm}^{-3}\left(1 \mathrm{~L}^{-1}\right)$, while the maximum reaches up to $0.3 \mathrm{~cm}^{-3}\left(\sim 300 \mathrm{~L}^{-1}\right)$. In comparison to a compilation of INP measurements presented recently by Kanji et al. (2017), the estimated range of $N_{\text {INP }}$ is shifted to somewhat smaller concentrations.

In Fig. 10, $N_{\text {small }}$ and $N_{\text {large }}$ for both Type 1 and Type 2 clouds are now presented in the same way as before $N_{\text {INP. }}$. In Type 1 clouds, especially for $N_{\text {small }}$ (upper left panel), we find concentrations between $2 \mathrm{~cm}^{-3}$ and more than $200 \mathrm{~cm}^{-3}$ down to temperatures of $-20^{\circ} \mathrm{C}(253 \mathrm{~K})$, well exceeding all INP estimations in this temperature range. However, also for $N_{\text {large }}$ (upper right panel), the cloud particle concentrations exceed the expected $N_{\text {INP }}$ by several orders of magnitude.

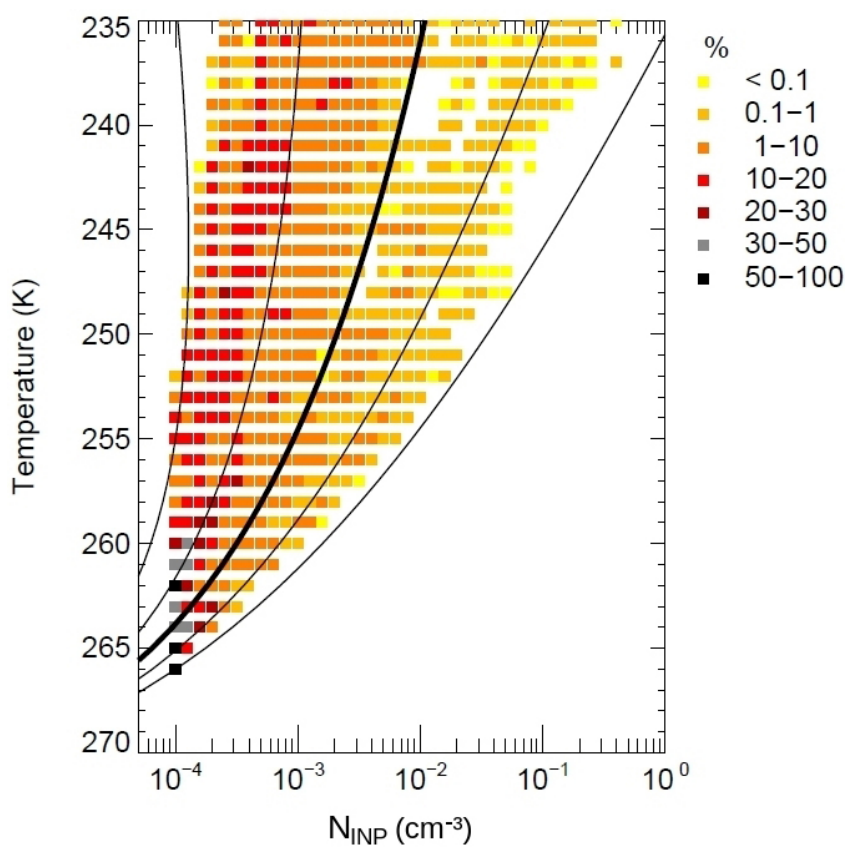

Figure 9. Frequencies of ice nucleating particle number concentrations $\left(N_{\mathrm{INP}}\right)$ vs. temperature for all measurement campaigns, colour coded by their frequency of occurrence. $N_{\text {INP }}$ is estimated from NIXE-CAPS measurements of aerosol concentrations $\left(D_{\mathrm{p}} 0.6-3 \mu \mathrm{m}\right)$ following DeMott et al. (2010). The black lines indicate INP concentrations for constant aerosol concentrations of 0.01 standard $\mathrm{cm}^{-3}$ (leftmost line), 0.1 standard $\mathrm{cm}^{-3}, 1$ standard $\mathrm{cm}^{-3}$ (thick line), 10 standard $\mathrm{cm}^{-3}$ and 100 standard $\mathrm{cm}^{-3}$ (rightmost line).

For colder temperatures, where the measured cloud particle number concentrations are lower, the estimated $N_{\text {INP }}$ are also mostly lower than the cloud particle concentrations. In general, we can exclude primary ice nucleation as a main contributor for cloud particles in the Type 1 clouds.

The $N_{\text {large }}$ of Type 2 clouds (lower-right panel) agree quite well with $N_{\text {INP }}$ for a wide range of temperatures. However, in warm areas, the cloud particle concentrations can be higher - they might represent large ice crystals sedimenting from upper layers, as mentioned in Sect. 3.1. For the colder regions, the agreement is consistent with the assumption that the Type 2 clouds we observed were formed by the WBF process (see Sect. 3.1) and that the formation of the initial ice crystals has been likely initiated by INPs immersed in the cloud droplets. $N_{\text {small }}$ is slightly increased in compari-

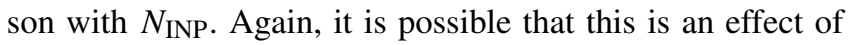
the CAS limited detectable concentration range, as discussed in Sect. 2.2. Detailed microphysical cloud simulations might help to further investigate this concentration range. 

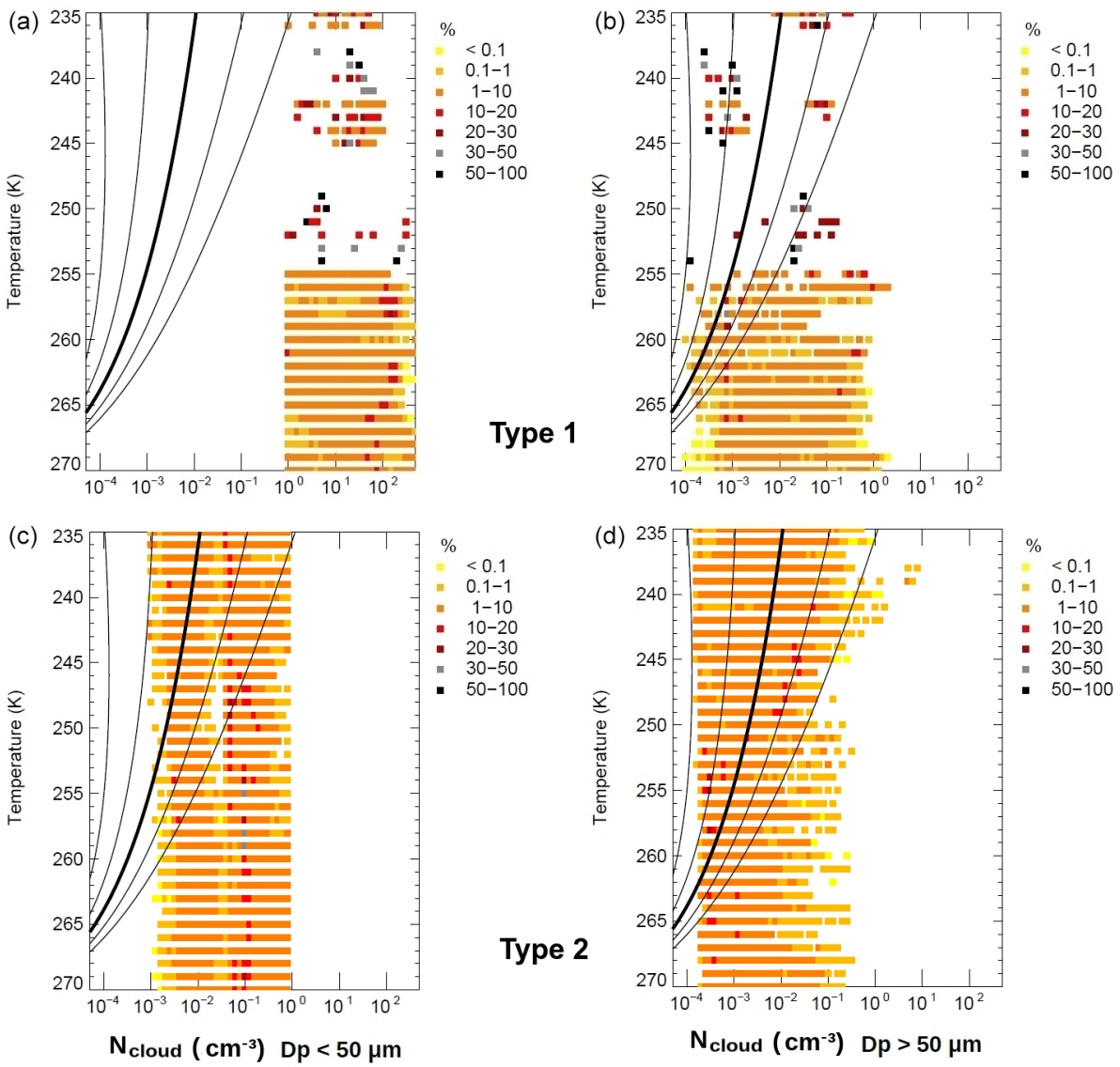

Figure 10. Same as Fig. 9, but frequencies of cloud particle number concentrations for $N_{\text {small }}$ (a, c) and $N_{\text {large }}(\mathbf{b}$, d). Top row: Type 1 clouds, bottom row: Type 2 clouds.

\subsection{Mpt cloud classification based on particle asphericity}

Size distributions, cloud particle number concentrations and comparisons with expected INP number concentrations provide little information on the cloud particle phase (see Sects. 3.1, 3.2). For further insights on the nature of the observed clouds, information on cloud particle asphericity is used.

As described in Sect. 2.2.1, for $N_{\text {small }}$ we define three groups with regard to AFs ( $1 \mathrm{~Hz}$ data of aspherical fractions) to help to classify the mpt clouds: (i) $\mathrm{AF}$ is $0 \%$ (zero), (ii) $\mathrm{AF}$ is 0 to $50 \%$ (low) and (iii) $\mathrm{AF}$ is 50 to $100 \%$ (high). AFs found in group (i) zero AF are classified as liquid, while AF observations in group (ii) low $\mathrm{AF}$ are regarded as mixedphase clouds (liquid and ice). Group (iii) high AF is most likely fully frozen. Particles $>100 \mu \mathrm{m}$ are mostly irregular (i.e. ice) in group (ii) and (iii). In group (i), large ice particles can occasionally be found. In the size range between 50 and $100 \mu \mathrm{m}$, the distinction between drizzle drops and ice particles is not possible, because the shadow images do not contain enough pixels to differentiate between spherical and irregular particles (see Sect. 2.2).
Figure 11 shows the aspherical fractions of Type 1 and 2 cloud particles vs. temperature; the data points are colour coded by the respective field campaigns. The horizontal lines show the 0 (liquid) and $-38^{\circ} \mathrm{C}$ (ice) temperature thresholds (273 and $235 \mathrm{~K}$, respectively). Looking at the data points in pure ice clouds below $-38^{\circ} \mathrm{C}(235 \mathrm{~K})$ it can be seen that most of the measurements are found in group (iii) high $\mathrm{AF}$ range. These AFs can therefore be associated with fully glaciated clouds. Note that Type 2 clouds show AFs comparable to those of cirrus clouds. The small particles found in relatively large number concentrations in this cloud type (see Sect. 3.1 and Table 6) must therefore be small ice crystals.

Due to the ambiguities of the polarisation measurement discussed in Sect. 2.2.1, AF covers a broad range, most often between 70 and $80 \%$. Note that even in the cirrus clouds the AF never reaches $100 \%$. A possible reason for this deviation can be columnar ice crystals: these are not well recognised by the CAS sensor (see Järvinen et al., 2016). Alternatively, frozen droplets might have maintained their compact, quasispherical shape. All aspherical fractions derived from CAS measurements must therefore be seen as minimum aspherical fractions. 


\subsection{Cloud type detection in the mpt regime}

The different cloud types that can be expected in the mpt regime (Table 1) can be identified by the combination of information about $N_{\text {small }}, N_{\text {large }}$ and the respective aspherical fractions (AFs) in each size range. Following this line, we developed algorithms to sort the mpt clouds - second by second - into the four cloud types, using the following criteria:

1. Mostly liquid Type 1a clouds are classified where $N_{\text {small }}$ is $>1 \mathrm{~cm}^{-3}$ and $\mathrm{AF}$ is zero (liquid).

2. Coexistence Type $1 \mathrm{~b}$ clouds are classified where $N_{\text {small }}$ is $>1 \mathrm{~cm}^{-3}$ and $\mathrm{AF}$ is low ( $<50 \%$, liquid and ice) and large ice crystals $N_{\text {large }}$ are present.

3. Secondary ice Type 1c clouds are classified where $N_{\text {small }}$ is $>1 \mathrm{~cm}^{-3}$, AF is high (ice) and large ice crystals $N_{\text {large }}$ are present.

4. WBF and large ice Type 2 clouds are classified where $N_{\text {small }}$ is $<1 \mathrm{~cm}^{-3}$, AF is high ( $>50 \%$, ice) and large ice crystals $N_{\text {large }}$ are present.

\subsection{Mpt cloud classification: results}

The mpt clouds observed in this study were probed under a wide range of meteorological conditions (see Sect. 2.1). We can therefore assume that these clouds have formed and evolved in different environments with regard to INP properties and updraughts, which are shown in the previous section to be the major parameters influencing the mpt cloud glaciation process.

For a comprehensive interpretation of the observed clouds, we divided the clouds into Arctic, midlatitude and tropical clouds, analysed the vertical velocities from the aircraft's meteorological data for the different cloud types (Fig. 12), estimated INP numbers (Fig. 13) and finally established distributions of the four mpt cloud categories (see Sect. 3.4) as a function of temperature (note that the temperatures are related to different altitudes depending on the geographical region, Fig. 14). The results are presented in Fig. 15.

\subsubsection{Arctic clouds}

The cloud types found during the field campaigns VERDI and RACEPAC are shown in Fig. 15a. For the probed temperature ranges ( 253 to $273 \mathrm{~K}$ - note that the temperature values in the figure indicate midbins), 50 to $80 \%$ of the mpt clouds belong to the Type $1 \mathrm{a} /$ mostly liquid (pink) category. Further, we find a low number of Type 1b/coexistence clouds (brown) and a small percentage of glaciated Type 2/WBF clouds (dark blue). As the estimated INP concentration based on aerosol measurements do not show clear conditions in the Arctic (see Fig. 13), a possible explanation for the large number of Type $1 \mathrm{a} /$ mostly liquid clouds could be a lack of biological INP at the time and location of our Arctic measurements as predicted in a model study by Wilson et al. (2015), so those clouds might not freeze at low temperatures (Shupe et al., 2008; Augustin-Bauditz et al., 2014). This might explain the lack of ice crystals, even though - possibly due to the low altitude of those warm layers (see Fig. 14) - the overall aerosol concentration is comparable to the midlatitudes.

The INP estimations for the Arctic (see Fig. 13a) have to be used with caution, because the "out of cloud" probed altitude range only covers warm temperatures, for which the INP estimation is not very sensitive to the measured aerosol concentrations.

However, an inspection of the vertical velocities measured during the Arctic campaigns in Fig. 12a indicates that $60 \%$ of the Type $1 \mathrm{a} /$ mostly liquid (pink) clouds are found in areas with very low updraughts, of $0.1 \mathrm{~m} \mathrm{~s}^{-1}$ and lower while mostly fluctuating around zero, and $40 \%$ are found in weak updraughts/downdraughts. Comparably weak updraughts are also frequently found in the Type 2/WBF (dark blue) clouds. This is to be expected, because the WBF regime develops in weak updraughts, implying that the trigger to transform a cloud from liquid to ice is the available INP concentration. The coexistence (brown) and secondary ice clouds were observed with low frequency $(<1 \%)$ in the Arctic and show a slightly wider spread in updraught velocities. In particular, higher updraughts occurred more often $(\sim 30 \%)$ in these clouds, which is consistent with the theoretical considerations shown in Fig. 2 for the coexistence regime. Note that, due to the uncertainties in the vertical velocity measurements, the statistical differences found between the cloud types should be regarded as an incentive for future investigations. While single data points might thus contain measurement errors, the distribution of observed vertical velocities is smooth and centred near zero, which is expected for the meteorological situations discussed in Sect. 2.1. Due to this, and because our data set consists of a large number of observations, we would like to point out the systematic differences found between cloud types and campaigns

\subsubsection{Midlatitude clouds}

At midlatitudes (COALESC field campaign), the largest cloud fractions are the fully glaciated Type $2 / \mathrm{WBF}$ clouds (dark blue in Fig. 15, middle panel). This is consistent with the assumption that at midlatitudes, the WBF process is the dominant process for cloud evolution (Boucher et al., 2013). More INP seem to be available that are ice active below $-10^{\circ} \mathrm{C}(263 \mathrm{~K})$. At temperatures warmer than $-20^{\circ} \mathrm{C}$ $(253 \mathrm{~K})$, the fraction of this cloud type is slowly reduced, while more and more Type $1 \mathrm{a} /$ mostly liquid clouds (pink in Fig. 15) and Type 1b/coexistence clouds (brown in Fig. 15) are found for higher temperatures. The WBF process depends on the presence of INPs (or seed ice from higher cloud layers), which are likely available in higher quantities at midlatitudes than in the Arctic (compare Sect. 3.5.1 
Type1 clouds, AF: Dp 20-50 $\mu \mathrm{m}$

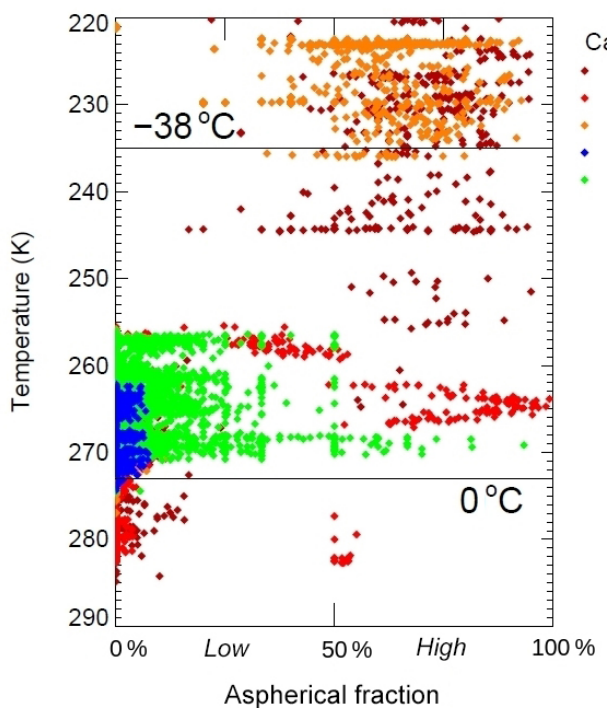

Type 2 clouds, AF: Dp 20-50 um

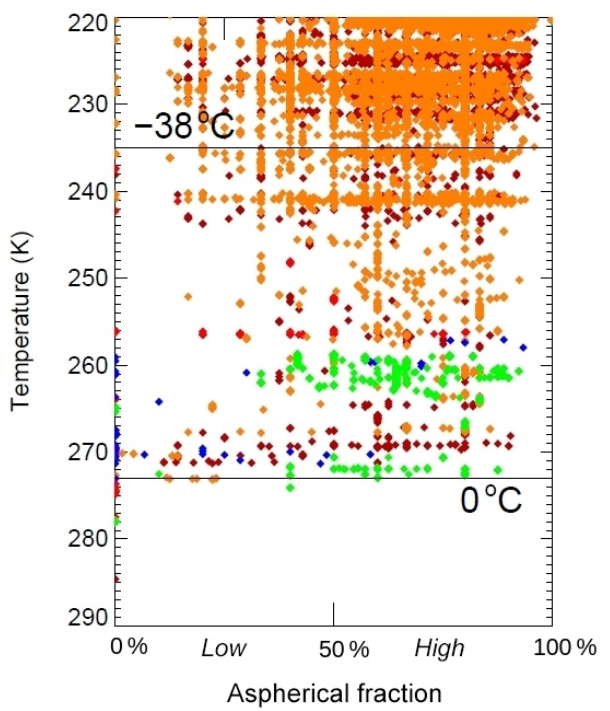

Figure 11. Aspherical fractions (AFs) for $D_{\mathrm{p}}=20$ to $50 \mu \mathrm{m}$. Type 1 clouds show a variety of AF. Type 2 shows AFs comparable to cirrus clouds - which is illustrated by observations from the ML-Cirrus campaign - throughout the temperature range.

Arctic

VERDI - fronts, high-pressure systems

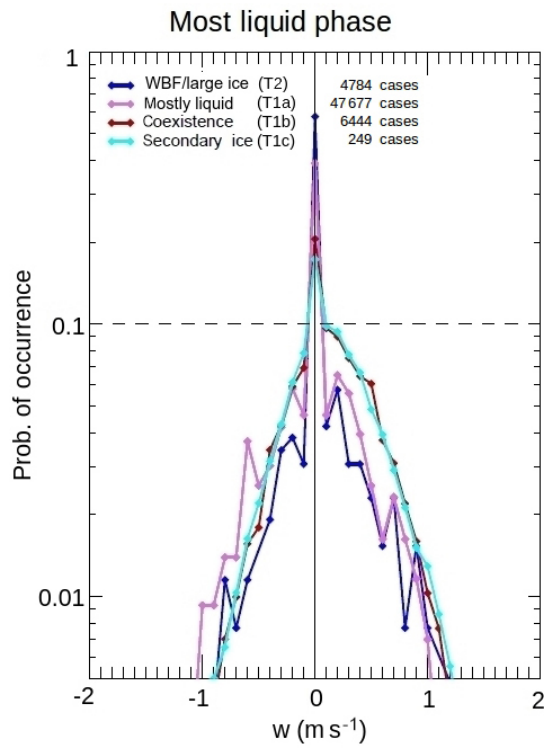

Midlatitudes

COALESC - fronts, high-pressure systems, convection

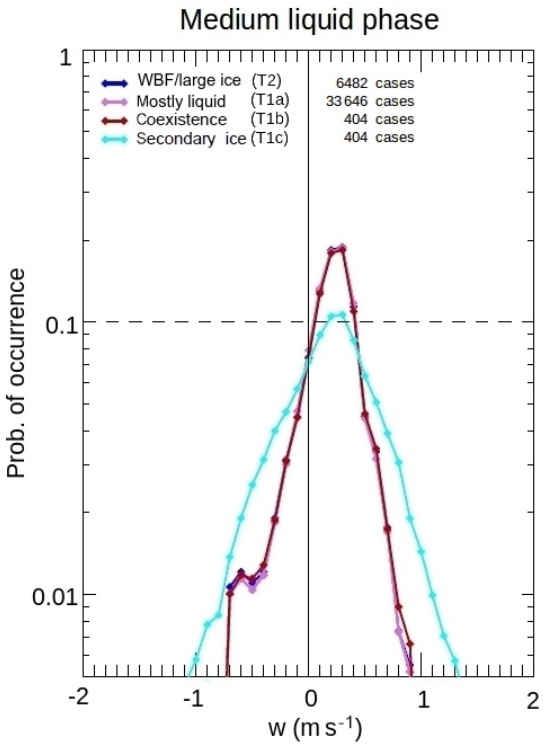

Tropics

ARCIDICON-CHUVAdry seasonal convection

Least liquid phase

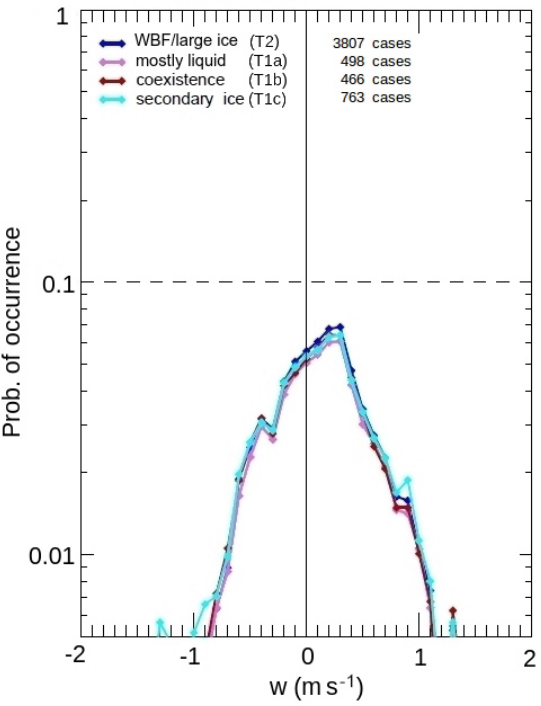

Figure 12. Frequency of occurrence for vertical velocities $(w)$ within mpt clouds during the campaigns VERDI (Arctic), COALESC (midlatitudes) and ACRIDICON-CHUVA (tropics) for the different cloud types $(T)$.

and Fig. 13). The varying occurrence of different cloud types with temperature - i.e. Type 1a clouds at higher temperatures (lower altitudes) and an increasing part of Type 2/WBF clouds with decreasing temperature (increasing altitude) might correspond to different INP regimes. At temperatures below about $-20{ }^{\circ} \mathrm{C}(253 \mathrm{~K})$, for example, efficient mineral dust INP might initiate the freezing process, while at warmer temperatures less frequently occurring biological particles most likely act as INP (Augustin-Bauditz et al., 2014; Kanji et al., 2017). In addition, the increasing fraction of Type $2 / \mathrm{WBF}$ clouds with decreasing temperature reflects the fact that the colder the environment, the higher the probability 

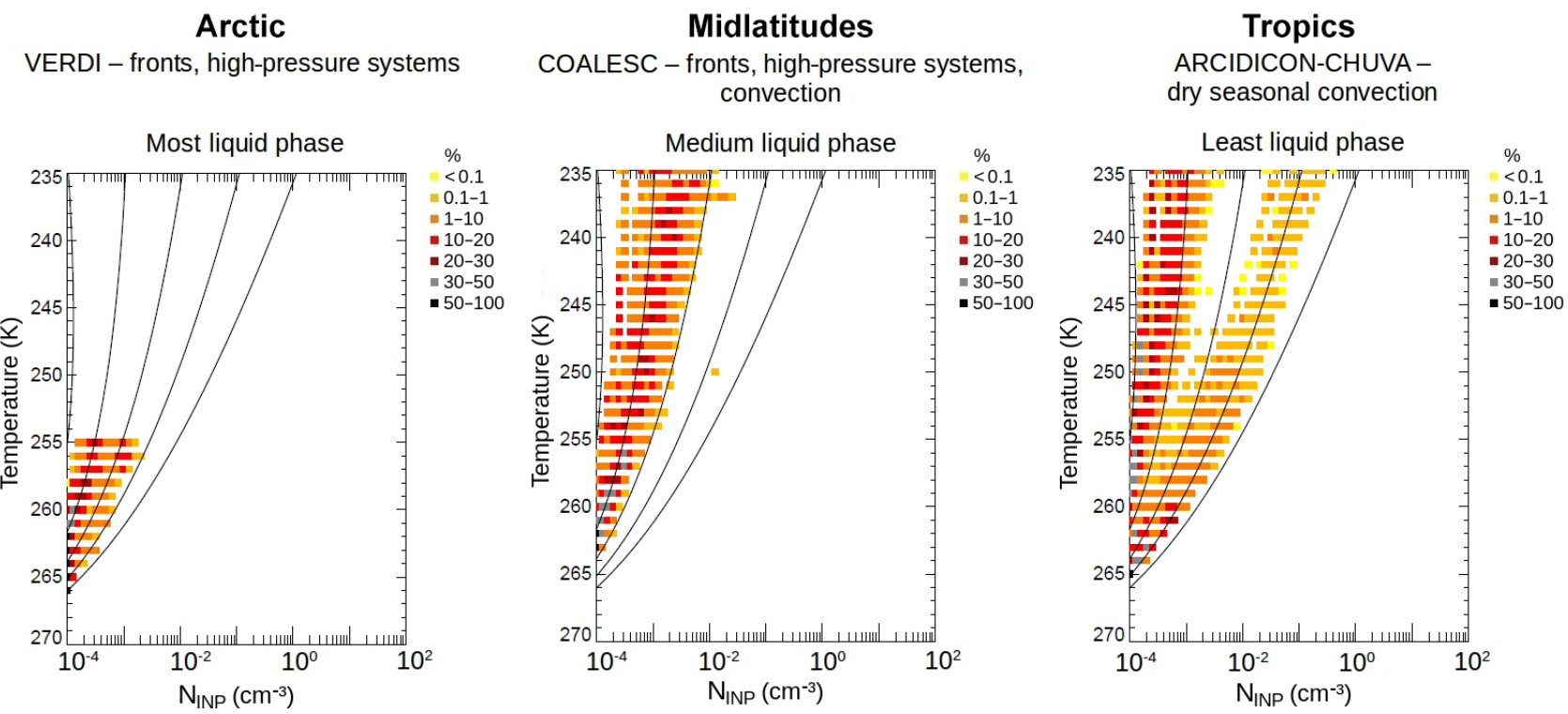

Figure 13. Frequencies of occurrence of INP concentrations ( $\left.N_{\mathrm{INP}}\right)$ vs. temperature during VERDI (Arctic), COALESC (midlatitudes) and ACRIDICON-CHUVA (tropics). INP number concentrations are estimated via aerosol concentrations for particles $>0.6 \mu \mathrm{m}$ following DeMott et al. (2010). The black lines indicate INP concentrations for constant aerosol concentrations of 0.01 (leftmost line), $0.1,1,10$ and $100 \mathrm{~cm}^{-3}$ (rightmost line).

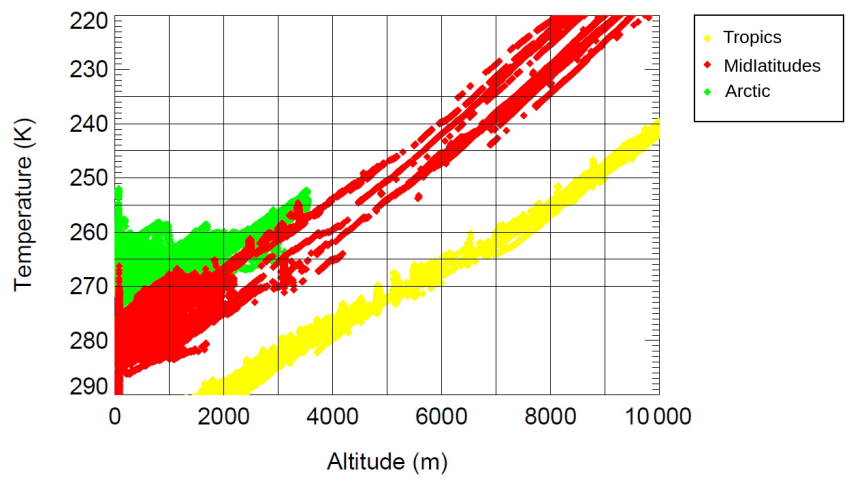

Figure 14. Temperature vs. altitude for the field campaigns VERDI and RACEPAC (Arctic), COALESC (midlatitudes) and ACRIDICON-CHUVA (tropics). The profile differs due to the varying latitudes.

that the $\mathrm{RH}_{\mathrm{w}}$ falls below $100 \%$ : with decreasing temperature, more and more droplets freeze and exploit the gas phase water when they grow. As a consequence, less gas-phase water is available the colder the temperature is. In the transition range between predominantly Type $1 \mathrm{a} /$ mostly liquid and only Type $2 / \mathrm{WBF}$ clouds (temperatures between -20 and $-10^{\circ} \mathrm{C}$ or 253 and $263 \mathrm{~K}$ ), Type $1 \mathrm{~b} /$ coexistence clouds appear, which we interpret as clouds in which the freezing process has started, but in which the $\mathrm{RH}_{\mathrm{w}}$ is still above $100 \%$ (blue curve slightly below $\mathrm{RH}_{\mathrm{w}}=100 \%$ in Fig. 2).

Type 1c/secondary ice clouds appear in midlatitude clouds more often than in the Arctic, which might reflect the in- creased availability of initial ice. It is unlikely that these small particles are shattering artefacts, because they often occur in clouds with no or few large ice particles - these large particles, however, are those that usually shatter (Korolev et al., 2011). In addition, as discussed in Sect. 2.3, based on IAT analysis, shattering could be almost excluded in the measurements. In contrast, the majority of those clouds occur at temperatures between -5 and $-13^{\circ} \mathrm{C}(268$ to $258 \mathrm{~K})$, which is an indication of an efficient Hallett-Mossop process having altered the cloud at slightly warmer temperatures. Note that the classification is aimed at the result of cloud transforming processes, not the cloud transformation itself. Which process precisely took place before the cloud section was probed cannot be proven with this $1 \mathrm{~Hz}$ data set.

At midlatitudes, Type 1a/mostly liquid, Type $1 \mathrm{~b} /$ coexistence and Type $2 / \mathrm{WBF}$ clouds show the same vertical velocity distributions (Fig. 12). The peak updraughts are slightly higher and the widths slightly narrower in comparison to the Arctic clouds. This is another hint that underscores the above-discussed dependence of the cloud categories on $\mathrm{RH}_{\mathrm{w}}$ : within the same vertical velocity range, the relative humidity can vary strongly depending on the available amount of water and the cloud development stage (cloud particle nucleation, sedimentation, evaporation). The Type 1c/secondary ice clouds show a different updraught distribution with faster vertical velocities, which might indicate that these clouds occurred in more turbulent environments, which is consistent with the idea that the cloud particles need to collide during the rime-splintering process. 


\subsubsection{Tropical clouds}

During the tropical field campaign ACRIDICON-CHUVA in convective towers, stronger updraughts and downdraughts were observed more frequently than during the other campaigns (Fig. 12, right panel). The records include extreme vertical velocities up to -10 and $+15 \mathrm{~m} \mathrm{~s}^{-1}$ (not shown here). However, these events were rarely observed, because due to flight safety, these cloud sections were mostly avoided. Velocities of 0.5 to $1.0 \mathrm{~m} \mathrm{~s}^{-1}$ were observed in more than $10 \%$ of all data points. The wider distribution of vertical velocities shows that the cloud dynamics are much stronger in the tropical clouds than at midlatitudes and in the Arctic.

In comparison to the other regions, fewer Type $1 \mathrm{a} /$ mostly liquid clouds are found in the tropics, also for warmer temperatures. This might be a consequence of sedimenting ice, or it might indicate a higher concentration of INPs that are already ice active at comparably high temperatures, pointing to biological INPs. This seems to be plausible for tropical regions, but is only partially confirmed by the INP estimate (see Fig. 13, right panel). The probed clouds occurred in both very clean air with fewer INPs than in the midlatitudes and in heavily polluted areas over fire clearance regions. A more detailed study on how the aerosol concentration affects the cloud-type distribution during ACRIDICON-CHUVA was done by Cecchini et al. (2017), based also on NIXE-CAPS aspherical fractions. The study shows that clouds in polluted environments contained more and smaller liquid water droplets and less ice, while clouds in clean conditions held more ice crystals and few liquid water droplets.

As a consequence of the higher vertical velocities in the convective towers, more Type 1b/coexistence clouds are observed than at midlatitudes or in the Arctic. A small number of the liquid droplets $<50 \mu \mathrm{m}$ survived down to the homogeneous drop freezing temperature $\left(\sim-38^{\circ} \mathrm{C}, 235 \mathrm{~K}\right)$ in cases where the vertical velocity was high enough (see also Fig. 2, red).

However, the Type 2/WBF and large ice clouds (Fig. 15, right panel) are the most frequent at all temperatures. Those large cloud particles might stem from sedimentation out of the cloud anvils, which usually consist of mostly large aggregates, or might be transported downwards in the strong downdraughts within the convective clouds (compare Jäkel et al., 2017).

It is, nevertheless, important to note again that due to security restrictions, the in situ measurements were mostly restricted to cloud regions with small updraught velocities (see Fig. 12), i.e. to young developing clouds or edges of convective towers. Due to this flight pattern, we most probably have probed conditions that favour the WBF process (consistent with Fig. 2, dark blue), even if those conditions might not be representative for tropical convective clouds in general. This part of the analysis should therefore be seen as an incentive for further studies and not be used as a basis for cloud type statistics in tropical dry seasonal convection.
In the tropical data set, the cloud type $1 \mathrm{c} /$ secondary ice is scarce at the lower levels - as at midlatitudes - but prevalent at cold temperatures, i.e. at high levels. The high concentrations of small aspherical particles might indicate a population of frozen droplets that quickly develop complex shapes in supersaturation. Alternatively, other ice multiplication processes (e.g. ice splintering or plasma-induced particle shattering due to lightning; see Leisner et al., 2014) might take place. Again, as discussed in Sect. 3.5.2, shattering artefacts can be almost excluded as the reason for the high number of small aspherical particles: large ice crystals appear at all temperatures up to $0^{\circ} \mathrm{C}(273 \mathrm{~K})$; the secondary ice cloud type $1 \mathrm{c}$ is, however, only observed at temperatures between -38 and $-20^{\circ} \mathrm{C}(235$ and $253 \mathrm{~K})$. Additionally, an analysis of interarrival times of the secondary ice cloud sections did not show shorter interarrival times than in other parts of the data set.

\section{Summary and conclusions}

The study presented here gives an overview of typical cloud properties observed between 0 and $-38^{\circ} \mathrm{C}$ ( 273 to $235 \mathrm{~K}$, mixed-phase temperature regime) and links the clouds at differing stages of glaciation to ice formation and evolution mechanisms. It gives hints to the relevance of cloud processes at different geographical locations and altitudes.

To this end, the cloud spectrometer NIXE-CAPS was deployed in four airborne field campaigns to conduct measurements of cloud particle sizes, number concentrations and, as an additional parameter, the cloud particles' asphericity. Based on the observations, which consist of $38.6 \mathrm{~h}$ within clouds, we developed algorithms based on the measurements of particle size distributions and aspherical fractions to identify four cloud types:

- Type 1a/mostly liquid refers to dense clouds consisting of mostly small droplets. All particles in the size range from 20 to $50 \mu \mathrm{m}$ are spherical. The few large cloud particles $>50 \mu \mathrm{m}$ might occasionally include ice crystals.

- Type $1 b /$ coexistence is dense clouds consisting of mostly small particles with a low percentage $(<50 \%)$ of small aspherical ice particles. Ice crystals $>50 \mu \mathrm{m}$ are present. The coexistence of liquid droplets and ice crystals is most probably due to supersaturation over both water and ice caused by higher vertical velocities.

- Type 1c/secondary ice refers to dense clouds consisting of mostly small particles between 3 and $50 \mu \mathrm{m}$ with a high percentage $(>50 \%)$ of aspherical ice particles. The aspherical fractions found are comparable to those of cirrus clouds; we thus conclude that these clouds are completely glaciated. The large cloud particles $>50 \mu \mathrm{m}$ are also frozen. The ice crystal numbers exceed the expected ice nuclei concentrations by several orders of magnitude, which suggests that the small crystals result 


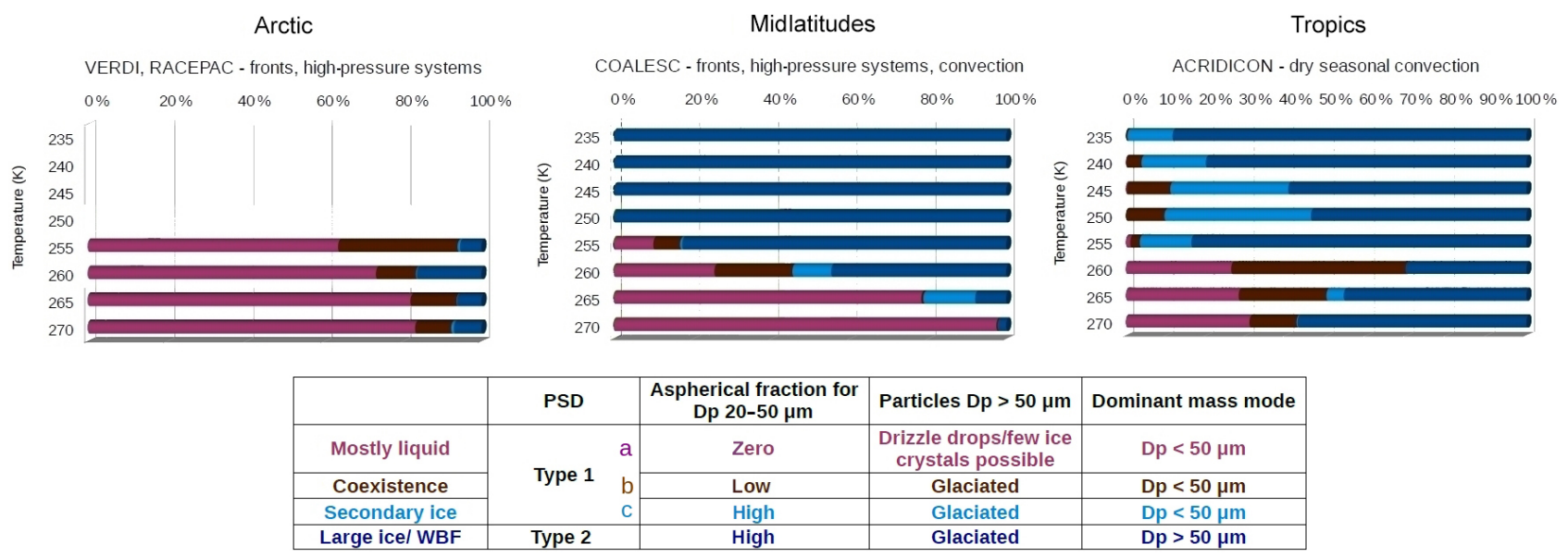

Figure 15. Occurrence of the cloud types defined in Sect. 3.3: Type 1a/mostly liquid clouds are dominated by small, exclusively spherical particles (for details on the particle size distributions (PSDs), see Sect. 3.1). They have high overall number concentrations. Type 1b/coexistence clouds are dense too, but do contain some small aspherical particles, indicating that a glaciation process has begun. The Type 1c/secondary ice cloud type is again very dense - the particle numbers exceed the INP concentration estimations by far (see Sect. 3.2). Here, most of the small particles in the size range between 20 and $50 \mu \mathrm{m}$ are aspherical; the cloud must therefore consist of ice. In contrast, clouds in the category Type $2 / \mathrm{WBF}$ and large ice show low overall number concentrations. These clouds are dominated by large ice particles which may resume from the Wegener-Bergeron-Findeisen process or, especially in the tropics, be large, sedimenting ice aggregates from cumulonimbus anvils.

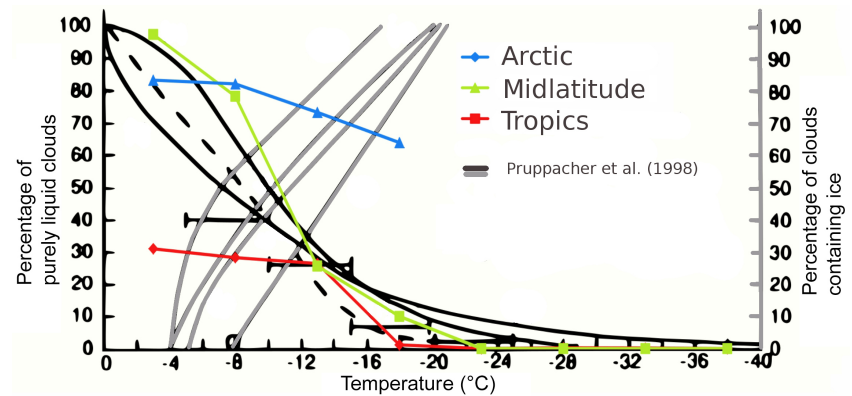

Figure 16. Percentage of clouds containing no ice (left $y$ axis) or ice (right axis); modified after Pruppacher et al. (1998). Black/grey lines: measurements reported in Pruppacher et al. (1998). The coloured lines refer to the left axis and represent measurements from this study. Blue: Arctic (VERDI/RACEPAC), green: midlatitude (COALESC), red: tropics (ACRIDICON-CHUVA).

from secondary ice production. Small ice crystal production by shattering can be almost excluded from IAT analysis of the specific situations.

- Type 2/WBF and large ice refers thin clouds with low number concentrations and a mass distribution dominated by large cloud particles $>50 \mu \mathrm{m}$. The aspherical fractions of the small particles are high and the large particles are frozen: these clouds are fully glaciated. The reduced number of small particles in comparison to the mostly liquid clouds can be explained by the WBF process. However, from the asphericity detection it is obvious that small ice crystals are present in WBF clouds with higher concentrations than large ice crystals. Alternatively, these clouds might consist of sedimenting aggregates. The cloud particle number concentrations agree reasonably well with the estimated ice nuclei concentrations.

We quantified the occurrence of these cloud types for Arctic, midlatitude and tropical regions.

For the Arctic, we observed mpt clouds for temperatures higher than $-20^{\circ} \mathrm{C}(253 \mathrm{~K})$. The most common were Type $1 \mathrm{a} /$ mostly liquid clouds, with a small percentage of Type 1b/coexistence and Type 2/WBF and large ice clouds. We hypothesise that this cloud type distribution is a result of low concentrations of ice active INPs, particularly biological INPs, during our field campaign in the Arctic. This hypothesis is in agreement with the low INP concentrations found for this region in a modelling study by Wilson et al. (2015), which is based on field measurements.

At midlatitudes, mpt clouds down to $-40{ }^{\circ} \mathrm{C}(233 \mathrm{~K})$ were probed, mostly in frontal systems with moderate updraughts between 0 and $0.5 \mathrm{~m} \mathrm{~s}^{-1}$. Here, the glaciated Type 2/WBF and large ice clouds dominate most of the temperature range, pointing to a sufficient availability of INPs. Only at temperatures warmer than $-20^{\circ} \mathrm{C}(253 \mathrm{~K})$ was an increasing fraction of Type $1 \mathrm{~b} /$ coexistence clouds and Type $1 \mathrm{c} /$ secondary ice clouds found. The temperature range for the secondary ice clouds is consistent with the preconditions for the HallettMossop process.

In the tropics, mostly moderate but also very strong vertical velocities were recorded. Correspondingly, the glaciated Type $2 / \mathrm{WBF}$ and large ice clouds dominate the measure- 
ments over all temperature ranges, but Type $1 \mathrm{~b} /$ coexistence clouds are also observed down to $-40^{\circ} \mathrm{C}(233 \mathrm{~K})$. The supercooled liquid droplets freeze homogeneously when transported to higher altitudes. Type $1 \mathrm{c} / \mathrm{secondary}$ ice clouds are observed at colder temperatures (higher altitudes) than at midlatitudes, indicating that ice-splintering processes other than the Hallett-Mossop process might be active here.

Pruppacher et al. (1998) summarise several studies (see Fig. 16) that tracked the percentage of clouds containing no ice crystals (left $y$ axis) or the percentage of clouds containing ice crystals (right $y$ axis) as a function of temperature. Their findings agree well with our observations at midlatitudes (green line in Fig. 16). It is noteworthy, however, that our observations in the Arctic (blue line) show higher liquid fractions, while in the tropical observations (red line) more ice clouds are found.

In general, the analysis of small cloud particle aspherical fractions advises against the assumption that all cloud particles smaller than $50 \mu \mathrm{m}$ are liquid. In contrast to previous assumptions, small particles were frequently found to be aspherical. The aspherical particle fractions are an important parameter for the identification of the four cloud types investigated here. Observations that contain this information (e.g. Mioche et al., 2017) can be used to extend the cloud statistics presented here. In case no small particle shapes are available, particle size distributions can be used to differ between the Type 1 cloud group (mostly liquid/coexistence/secondary ice clouds) and the Type 2 clouds (WBF and large ice clouds). A sufficiently large database would, for example, allow the quantification of the efficiency of the WBF process with regard to temperature and location. Along these lines, this study might serve as a starting point for a growing cloud type database in the mpt regime.

Data availability. The data are available through mission-based databases. They can be accessed after signing a data agreement. The permanent URLs are ACRIDICON-CHUVA via the DLR HALO database, https://halo-db.pa.op.dlr.de/, last access 5 October 2017. VERDI/RACEPAC via the DShip platform of AWI, https://dms. awi.de/, last access 17 October 2013. COALESC via the MetOffice FAAM database, http://data.ceda.ac.uk//badc/faam/data/2011/, last access 5 October 2017.

Competing interests. The authors declare that they have no conflict of interest.

Special issue statement. This article is part of the special issue "VERDI - Vertical Distribution of Ice in Arctic Clouds (ACP/AMT inter-journal SI)", resulting from the conference EGU2016, Vienna, Austria, 17 to 22 April 2016, as well as of the special issue "The ACRIDICON-CHUVA campaign to study deep convective clouds and precipitation over Amazonia using the new German HALO research aircraft (ACP/AMT inter-journal SI)".
Acknowledgements. This work was supported by the Max Planck society, the DFG (Deutsche Forschungsgemeinschaft, German Research Foundation) Priority Program SPP 1294, the German Aerospace Center (DLR), and the FAPESP (São Paolo Research Foundation). Heike Wex is currently funded by DFG within the Ice Nuclei research UnIT (INUIT, FOR 1525), WE 4722/1-2. We thank Martin Schnaiter and Emma Järvinen for the fruitful discussions during the RICE03 campaign.

We also thank two anonymous reviewers for their thorough comments which helped to improve the quality of this paper.

The article processing charges for this open-access

publication were covered by a Research

Centre of the Helmholtz Association.

Edited by: Corinna Hoose

Reviewed by: two anonymous referees

\section{References}

Augustin-Bauditz, S., Wex, H., Kanter, S., Ebert, M., Niedermeier, D., Stolz, F., Prager, A., and Stratmann, F.: The immersion mode ice nucleation behavior of mineral dusts: A comparison of different pure and surface modified dusts, Geophys. Res. Lett., 41, 7375-7382, 2014.

Baumgardner, D., Jonsson, H., Dawson, W., O'Connor, D., and Newton, R.: The cloud, aerosol and precipitation spectrometer: a new instrument for cloud investigations, Atmos. Res., 59/60, 251-264, https://doi.org/10.1016/S0169-8095(01)001193, 2001.

Baumgardner, D., Newton, R., Krämer, M., Meyer, J., Beyer, A., Wendisch, M., and Vochezer, P.: The Cloud Particle Spectrometer with Polarization Detection (CPSPD): A next generation open-path cloud probe for distinguishing liquid cloud droplets from ice crystals, Atmos. Res., 142, 2-14, https://doi.org/10.1016/j.atmosres.2013.12.010, 2014.

Baumgardner, D., Abel, S. J., Axisa, D., Cotton, R., Crosier, J., Field, P., Gurganus, C., Heymsfield, A., Korolev, A., Krämer, M., Lawson, P., McFarquhar, G., Ulanowski, Z., and Um, J.: Cloud Ice Properties: In Situ Measurement Challenges; Chapter 9 of "Ice Formation and Evolution in Clouds and Precipitation: Measurement and Modeling Challenges", Meteorol. Monogr., 58, 9.1-9.23, https://doi.org/10.1175/AMSMONOGRAPHS-D16-0011.1, 2017.

Boucher, O., Randall, D., Artaxo, P., Bretherton, C., Feingold, G., Forster, P., Kerminen, V.-M., Kondo, Y., Liao, H., Lohmann, U., Rasch, P., Satheesh, S. K., Sherwood, S., Stevens, B., and Zhang, X. Y.: Clouds and Aerosols, Climate Change 2013: The Physical Science Basis, Contribution of Working Group I to the Fifth Assessment Report of the Intergovernmental Panel on Climate Change, edited by: Stocker, T. F., Qin, D., Plattner, G.-K., Tignor, M., Allen, S. K., Boschung, J., Nauels, A., Xia, Y., Bex, V., and Midgley, P. M., cambridge University Press, Cambridge, UK and New York, NY, USA, https://www.ipcc.ch/report/ar5/ (last access: 5 October 2017), 2013.

Bühl, J., Ansmann, A., Seifert, P., Baars, H., and Engelmann, R.: Toward a quantitative characterization of heterogeneous ice formation with lidar/radar: Comparison of CALIPSO/CloudSat 
with ground-based observations, Geophys. Res. Lett., 40, 44044408, 2013.

Cecchini, M. A., Machado, L. A. T., Wendisch, M., Costa, A., Krämer, M., Andreae, M. O., Afchine, A., Albrecht, R. I., Artaxo, P., Borrmann, S., Fütterer, D., Klimach, T., Mahnke, C., Martin, S. T., Minikin, A., Molleker, S., Pardo, L. H., Pöhlker, C., Pöhlker, M. L., Pöschl, U., Rosenfeld, D., and Weinzierl, B.: Illustration of microphysical processes of Amazonian deep convective clouds in the Gamma phase space: Introduction and potential applications, Atmos. Chem. Phys. Discuss., https://doi.org/10.5194/acp-2017-185, in review, 2017.

Curry, J. A., Schramm, J. L., Rossow, W. B., and Randall, D.: Overview of Arctic Cloud and Radiation Characteristics, J. Clim., 9, 1731-1764, https://doi.org/10.1175/15200442(1996)009<1731:OOACAR>2.0.CO;2, 1996.

DeMott, P. J., Prenni, A. J., Liu, X., Kreidenweis, S. M., Petters, M. D., Twohy, C. H., Richardson, M. S., Eidhammer, T., and Rogers, D. C.: Predicting global atmospheric ice nuclei distributions and their impacts on climate, Proc. Natl. Acad. Sci. USA, 107, 11217-11222, https://doi.org/10.1073/pnas.0910818107, 2010.

Ehrlich, A., Wendisch, M., Bierwirth, E., Gayet, J.-F., Mioche, G., Lampert, A., and Mayer, B.: Evidence of ice crystals at cloud top of Arctic boundary-layer mixed-phase clouds derived from airborne remote sensing, Atmos. Chem. Phys., 9, 9401-9416, https://doi.org/10.5194/acp-9-9401-2009, 2009.

Field, P., Lawson, R. P., Brown, P. R. A., Lloyd, G., Westbrook, C., Moisseev, D., Miltenberger, A., Nenes, A., Blyth, A., Choularton, T., Connolly, P., Buehl, J., Crosier, J., Cui, Z., Dearden, C., DeMott, P., Flossmann, A., Heymsfield, A., Huang, Y., Kalesse, H., Kanji, Z. A., Korolev, A., Kirchgaessner, A., Lasher-Trapp, S., Leisner, T., McFarquhar, G., Phillips, V., Stith, J., and Sullivan, S.: Ice Formationand Evolution in Clouds and Precipitation: Measurement and Modeling Challenges, Chapter 7: Secondary Ice Production - current state of the science and recommendations for the future, Meteorol. Monogr., 58, 58, 7.1-7.20, 2017.

Field, P. R., Heymsfield, A. J., and Bansemer, A.: Shattering and Particle Interarrival Times Measured by Optical Array Probes in Ice Clouds, J. Atmos. Ocean. Technol., 23, 1357-1371, https://doi.org/10.1175/JTECH1922.1, 2006.

Field, P. R., Lawson, R. P., Brown, P. R. A., Lloyd, G., Westbrook, C., Moisseev, D., Miltenberger, A., Nenes, A., Blyth, A., Choularton, T., Connolly, P., Buehl, J., Crosier, J., Cui, Z., Dearden, C., DeMott, P., Flossmann, A., Heymsfield, A., Huang, Y., Kalesse, H., Kanji, Z. A., Korolev, A., Kirchgaessner, A., LasherTrapp, S., Leisner, T., McFarquhar, G., Phillips, V., Stith, J., and Sullivan, S.: Chapter 7, Secondary Ice Production - current state of the science and recommendations for the future, Meteor. Mon., 0, https://doi.org/10.1175/AMSMONOGRAPHS-D16-0014.1, 2015.

Findeisen, W., Volken, E., Giesche, A. M., and Brönnimann, S.: Colloidal meteorological processes in the formation of precipitation, Meteorol. Z., 24, 443-454, https://doi.org/10.1127/metz/2015/0675, 2015.

Frey, W.: Airborne in situ measurements of ice particles in the tropical tropopause layer, Ph.D. thesis, Johannes GutenbergUniversität, 2011.

Hallett, J. and Mossop, C.: Production of secondary ice particles during the riming process, Nature, 249, 26-28, 1974.
Jäkel, E., Wendisch, M., Krisna, T. C., Ewald, F., Kölling, T., Jurkat, T., Voigt, C., Cecchini, M. A., Machado, L. A. T., Afchine, A., Costa, A., Krämer, M., Andreae, M. O., Pöschl, U., Rosenfeld, D., and Yuan, T.: Vertical distribution of the particle phase in tropical deep convective clouds as derived from cloud-side reflected solar radiation measurements, Atmos. Chem. Phys., 17, 9049-9066, https://doi.org/10.5194/acp-17-9049-2017, 2017.

Järvinen, E., Schnaiter, M., Mioche, G., Jourdan, O., Shcherbakov, V. N., Costa, A., Afchine, A., Krämer, M., Heidelberg, F., Jurkat, T., Voigt, C., Schlager, H., Nichman, L., Gallagher, M., Hirst, E., Schmitt, C., Bansemer, A., Heymsfield, A., Lawson, P., Tricoli, U., Pfeilsticker, K., Vochezer, P., Möhler, O., and Leisner, T.: Quasi-spherical Ice in Convective Clouds, J. Atmos. Sci., 73, 3885-3910, https://doi.org/10.1175/JAS-D-15-0365.1, 2016.

Kanji, Z., Ladino, L. A., Wex, H., Boose, Y., Burkert-Kohn, M., Cziczo, D. J., and Krämer, M.: Ice Formation and Evolution in Clouds and Precipitation: Measurement and Modeling Challenges, Chapter 1: Overview of Ice Nucleating Particles, Meteorol. Mon., 58, 1.1-1.33, 2017.

Klingebiel, M., de Lozar, A., Molleker, S., Weigel, R., Roth, A., Schmidt, L., Meyer, J., Ehrlich, A., Neuber, R., Wendisch, M., and Borrmann, S.: Arctic low-level boundary layer clouds: in situ measurements and simulations of mono- and bimodal supercooled droplet size distributions at the top layer of liquid phase clouds, Atmos. Chem. Phys., 15, 617-631, https://doi.org/10.5194/acp-15-617-2015, 2015.

Knollenberg, R. G.: The Optical Array: An Alternative to Scattering or Extinction for Airborne Particle Size Determination, J. Appl. Meteorol., 9, 86-103, https://doi.org/10.1175/15200450(1970)009<0086:TOAAAT>2.0.CO;2, 1970.

Koop, T., Luo, B., Tsias, A., and Peter, T.: Water activity as the determinant for homogeneous ice nucleation in aqueous solutions, Nature, 406, 611-614, 2000.

Korolev, A.: Limitations of the Wegener-Bergeron-Findeisen Mechanism in the Evolution of Mixed-Phase Clouds, J. Atmos. Sci., 64, 3372-3375, https://doi.org/10.1175/JAS4035.1, 2007.

Korolev, A. and Field, P. R.: Assessment of the performance of the inter-arrival time algorithm to identify ice shattering artifacts in cloud particle probe measurements, Atmos. Meas. Tech., 8, 761777, https://doi.org/10.5194/amt-8-761-2015, 2015.

Korolev, A. and Sussman, B.: A Technique for Habit Classification of Cloud Particles, J. Atmos. Ocean. Tech., 17, 1048-1057, https://doi.org/10.1175/15200426(2000)017<1048:ATFHCO>2.0.CO;2, 2000.

Korolev, A., Emery, E., Strapp, J., Cober, S., Isaac, G., Wasey, M., and Marcotte, D.: Small ice particles in tropospheric clouds: Fact or artifact? Airborne Icing Instrumentation Evaluation Experiment, B. Am. Meteorol. Soc., 92, 967-973, 2011.

Korolev, A., Emery, E., and Creelman, K.: Modification and Tests of Particle Probe Tips to Mitigate Effects of Ice Shattering, J. Atmos. Oceanic Technol., 30, 690-708, https://doi.org/10.1175/JTECH-D-12-00142.1, 2013.

Lachlan-Cope, T., Listowski, C., and O'Shea, S.: The microphysics of clouds over the Antarctic Peninsula - Part 1: Observations, Atmos. Chem. Phys., 16, 15605-15617, https://doi.org/10.5194/acp-16-15605-2016, 2016.

Lawson, R. P., Woods, S., and Morrison, H.: The Microphysics of Ice and Precipitation Development in Tropical Cumulus Clouds, 
J. Atmos. Sci., 72, 2429-2445, https://doi.org/10.1175/JAS-D14-0274.1, 2015.

Leisner, T., Duft, D., Möhler, O., Saathoff, H., Schnaiter, M., Henin, S., Stelmaszczyk, K., Petrarca, M., Delagrange, R., Hao, Z., Lüder, J., Petit, Y., Rohwetter, P., Kasparian, J., Wolf, JP., and Wöste, L.: Laser-induced plasma cloud interaction and ice multiplication under cirrus cloud conditions, Proc. Natl. Acad. Sci. USA, 110, 10106-10110, 2014.

Lloyd, G., Choularton, T. W., Bower, K. N., Crosier, J., Jones, H., Dorsey, J. R., Gallagher, M. W., Connolly, P., Kirchgaessner, A. C. R., and Lachlan-Cope, T.: Observations and comparisons of cloud microphysical properties in spring and summertime Arctic stratocumulus clouds during the ACCACIA campaign, Atmos. Chem. Phys., 15, 3719-3737, https://doi.org/10.5194/acp15-3719-2015, 2015.

Luebke, A. E., Afchine, A., Costa, A., Grooß, J.-U., Meyer, J., Rolf, C., Spelten, N., Avallone, L. M., Baumgardner, D., and Krämer, M.: The origin of midlatitude ice clouds and the resulting influence on their microphysical properties, Atmos. Chem. Phys., 16, 5793-5809, https://doi.org/10.5194/acp-16-5793-2016, 2016.

Meyer, J.: Ice Crystal Measurements with the New Particle Spectrometer NIXE-CAPS, PhD, Bergische Universitaet Wuppertal, Jülich, http://juser.fz-juelich.de/record/22871 (last access: Please provide last acces date.), record converted from VDB: 12.11.2012; Wuppertal, University, 2012.

Mioche, G., Jourdan, O., Delanoë, J., Gourbeyre, C., Febvre, G., Dupuy, R., Szczap, F., Schwarzenboeck, A., and Gayet, J.-F.: Characterization of Arctic mixed-phase cloud properties at small scale and coupling with satellite remote sensing, Atmos. Chem. Phys. Discuss., https://doi.org/10.5194/acp-2017-93, in review, 2017.

Nichman, L., Fuchs, C., Järvinen, E., Ignatius, K., Höppel, N. F., Dias, A., Heinritzi, M., Simon, M., Tröstl, J., Wagner, A. C., Wagner, R., Williamson, C., Yan, C., Connolly, P. J., Dorsey, J. R., Duplissy, J., Ehrhart, S., Frege, C., Gordon, H., Hoyle, C. R., Kristensen, T. B., Steiner, G., McPherson Donahue, N., Flagan, R., Gallagher, M. W., Kirkby, J., Möhler, O., Saathoff, H., Schnaiter, M., Stratmann, F., and Tomé, A.: Phase transition observations and discrimination of small cloud particles by light polarization in expansion chamber experiments, Atmos. Chem. Phys., 16, 3651-3664, https://doi.org/10.5194/acp16-3651-2016, 2016.

Osborne, S. R., Abel, S. J., Boutle, I. A., and Marenco, F.: Evolution of Stratocumulus Over Land: Comparison of Ground and Aircraft Observations with Numerical Weather Prediction Simulations, Bound.-Lay. Meteorol., 153, 165-193, https://doi.org/10.1007/s10546-014-9944-0, 2014.

Pruppacher, H. R., Klett, J. D., and Wang, P. K.: Microphysics of clouds and precipitation, Taylor \& Francis, 1998.

Rossow, W. B. and Schiffer, R. A.: ISCCP cloud data products, B. Am. Meteorol. Soc., 72, 2-20, 1991.

Shupe, M. D. and Intrieri, J. M.: Cloud Radiative Forcing of the Arctic Surface: The Influence of Cloud Properties, Surface Albedo, and Solar Zenith Angle, J. Clim., 17, 616-628, https://doi.org/10.1175/15200442(2004)017<0616:CRFOTA>2.0.CO;2, 2004.

Shupe, M. D., Daniel, J. S., de Boer, G., Eloranta, E. W., Kollias, P., Luke, E. P., Long, C. N., Turner, D. D., and Verlinde, J.: A Focus
On Mixed-Phase Clouds, B. Am. Meteorol. Soc., 89, 1549-1562, https://doi.org/10.1175/2008BAMS2378.1, 2008.

Storelvmo, T. and Tan, I.: The Wegener-Bergeron-Findeisen process - Its discovery and vital importance for weather and climate, Meteorol. Z., 24, 455-461, https://doi.org/10.1127/metz/2015/0626, 2015.

Taylor, J. W., Choularton, T. W., Blyth, A. M., Liu, Z., Bower, K. N., Crosier, J., Gallagher, M. W., Williams, P. I., Dorsey, J. R., Flynn, M. J., Bennett, L. J., Huang, Y., French, J., Korolev, A., and Brown, P. R. A.: Observations of cloud microphysics and ice formation during COPE, Atmos. Chem. Phys., 16, 799-826, https://doi.org/10.5194/acp-16-799-2016, 2016.

Wendisch, M. and Brenguier, J.-L.: Airborne measurements for environmental research: methods and instruments, John Wiley \& Sons, 2013.

Wendisch, M., Yang, P., and Ehrlich, A.: Amplified climate changes in the Arctic: Role of clouds and atmospheric radiation, Sitzungsberichte der Saechsischen Akademie der Wissenschaften zu Leipzig, Mathematisch-Naturwissenschaftliche Klasse, 132, 134, 2013.

Wendisch, M., Pöschl, U., Andreae, M. O., Machado, L. A. T., Albrecht, R., Schlager, H., Rosenfeld, D., Martin, S. T., Abdelmonem, A., Afchine, A., Araùjo, A., Artaxo, P., Aufmhoff, H., Barbosa, H. M. J., Borrmann, S., Braga, R., Buchholz, B., Cecchini, M. A., Costa, A., Curtius, J., Dollner, M., Dorf, M., Dreiling, V., Ebert, V., Ehrlich, A., Ewald, F., Fisch, G., Fix, A., Frank, F., Fütterer, D., Heckl, C., Heidelberg, F., Hüneke, T., Jäkel, E., Järvinen, E., Jurkat, T., Kanter, S., Kästner, U., Kenntner, M., Kesselmeier, J., Klimach, T., Knecht, M., Kohl, R., Kölling, T., Krämer, M., Krüger, M., Krisna, T. C., Lavric, J. V., Longo, K., Mahnke, C., Manzi, A. O., Mayer, B., Mertes, S., Minikin, A., Molleker, S., Münch, S., Nillius, B., Pfeilsticker, K., Pöhlker, C., Roiger, A., Rose, D., Rosenow, D., Sauer, D., Schnaiter, M., Schneider, J., Schulz, C., de Souza, R. A. F., Spanu, A., Stock, P., Vila, D., Voigt, C., Walser, A., Walter, D., Weigel, R., Weinzierl, B., Werner, F., Yamasoe, M. A., Ziereis, H., Zinner, T., and Zöger, M.: The ACRIDICON-CHUVA campaign: Studying tropical deep convective clouds and precipitation over Amazonia using the new German research aircraft HALO, B. Am. Meteorol. Soc., 97, 1885-1908, https://doi.org/10.1175/BAMS-D-14$00255.1,2016$.

Wendisch, M., Brückner, M., Burrows, J. P., Crewell, S., Dethloff, K., Ebell, K., Lüpkes, C., Macke, A., Notholt, J., Quaas, J., Rinke, A., and Tegen, I.: Understanding Causes and Effects of Rapid Warming in the Arctic, EOS, 98 pp., https://doi.org/10.1029/2017EO064803, 2017.

Wilson, T. W., Ladino, L. A., Alpert, P. A., Breckels, M. N., Brooks, I. M., Browse, J., Burrows, S. M., Carslaw, K. S., Huffman, J. A., Judd, C., Kilthau, W. P., Mason, R. H. McFiggans, G., Miller, L. A., Najera, J. J., Polishchuk, E., Rae, S., Schiller, C. L., Si, M. Temprado, J. V., Whale, T. F., Wong, J. P. S., Wurl, O., YakobiHancock, J. D., Abbatt, J. P. D., Aller, J. Y., Bertram, A. K., Knopf, D. A., and Murray, B. J.: A marine biogenic source of atmospheric ice-nucleating particles, Nature, 525, 234-238, 2015.

Yano, J.-I. and Phillips, V. T. J.: Ice-Ice Collisions: An Ice Multiplication Process in Atmospheric Clouds, J. Atmos. Sci., 68, 322-333, https://doi.org/10.1175/2010JAS3607.1, 2011. 